\title{
Molecular markers and potential therapeutic targets in non-WNT/non-SHH (group 3 and group 4) medulloblastomas
}

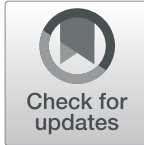

\author{
Otília Menyhárt ${ }^{1,2}$, Felice Giangaspero ${ }^{3,4}$ and Balázs Győrffy ${ }^{1,2^{*}}$
}

\begin{abstract}
Childhood medulloblastomas (MB) are heterogeneous and are divided into four molecular subgroups. The provisional non-wingless-activated (WNT)/non-sonic hedgehog-activated (SHH) category combining group 3 and group 4 represents over two thirds of all MBs, coupled with the highest rates of metastases and least understood pathology. The molecular era expanded our knowledge about molecular aberrations involved in MB tumorigenesis, and here, we review processes leading to non-WNT/non-SHH MB formations.

The heterogeneous group 3 and group 4 MBs frequently harbor rare individual genetic alterations, yet the emerging profiles suggest that infrequent events converge on common, potentially targetable signaling pathways. A mutual theme is the altered epigenetic regulation, and in vitro approaches targeting epigenetic machinery are promising. Growing evidence indicates the presence of an intermediate, mixed signature group along group 3 and group 4, and future clarifications are imperative for concordant classification, as misidentifying patient samples has serious implications for therapy and clinical trials.

To subdue the high MB mortality, we need to discern mechanisms of disease spread and recurrence. Current preclinical models do not represent the full scale of group 3 and group 4 heterogeneity: all of existing group 3 cell lines are MYC-amplified and most mouse models resemble MYC-activated MBs. Clinical samples provide a wealth of information about the genetic divergence between primary tumors and metastatic clones, but recurrent MBs are rarely resected. Molecularly stratified treatment options are limited, and targeted therapies are still in preclinical development. Attacking these aggressive tumors at multiple frontiers will be needed to improve stagnant survival rates.
\end{abstract}

Keywords: Medulloblastoma, Prognostic biomarker, Risk stratification, Survival, Non-WNT/non-SHH, Group 3, Group 4

\section{Introduction}

Medulloblastoma (MB) is the most common pediatric brain tumor [1], with a culminating incidence among children before the age of five [2]. Unfortunately, disease dissemination is an early event, and as many as $40 \%$ of patients carry metastases already at diagnosis [3], with a grim outlook for survival [4]. Metastatic disease and tumor recurrence are responsible for the stagnant survival

\footnotetext{
* Correspondence: gyorffy.balazs@ttk.mta.hu

2nd Department of Pediatrics, Semmelweis University, Túzoltó u. 7-9, Budapest H-1094, Hungary

${ }^{2}$ MTA TTK Lendület Cancer Biomarker Research Group, Institute of Enzymology, Hungarian Academy of Sciences, Magyar tudósok körútja 2, Budapest H-1117, Hungary

Full list of author information is available at the end of the article
}

rates of the past decades [1,2], while survivors frequently face treatment-related adverse effects [1].

The current consensus agrees upon four distinct molecular entities within MBs: wingless-activated (WNT), sonic hedgehog-activated ( $\mathrm{SHH}$ ), group 3, and group $4 \mathrm{MBs}$ [5], each characterized by specific mutations, copy number alterations, transcriptomic/methylomic profiles, and clinical outcomes [6-9]. Subgroup assignment is prognostic with markedly different survival rates; a 5-year overall survival (OS) is as high as $95 \%$ in WNT, while group 3 patients feature the worst (45-60\%), with the shortest survival among infants. An intermediate (75-80\%) OS characterizes group 4 and SHH MBs, although it also depends on histology, presence of metastases, and molecular abnormalities such as mutations and oncogene amplifications [10-14].

(C) The Author(s). 2019 Open Access This article is distributed under the terms of the Creative Commons Attribution 4.0 International License (http://creativecommons.org/licenses/by/4.0/), which permits unrestricted use, distribution, and 
Group 3 and group $4 \mathrm{MBs}$ are more related to each other than to WNT and SHH and appear as non-WNT/ non-SHH in the revised 2016 WHO classification [15], yet they are molecularly and clinically heterogeneous with diverse outcomes [16-18]. The provisional non-WNT/non-SHH category presents a complex challenge as these tumors represent over two thirds of all MBs, coupled with the highest rates of disseminated disease and least understood pathology.

Here we aim to summarize the present state of non-WNT/non-SHH MB research, with a particular focus on molecular similarities and differences between group 3 and group 4 MBs.

\section{Clinical attributes of group 3 and group 4 MBs}

The demography of group 3 or group $4 \mathrm{MB}$ patients overlaps although the subtypes are associated with radically different prognosis and clinical outcome.

Group 3 MBs account for approximately 25\% of all cases, predominantly among infants and children, with a peak diagnosis between ages 3 and 5 years and almost never in adults; hence, in adults, only three MB subgroups can be differentiated $[19,20]$ (Fig. 1). The male-to-female ratio is approximately two to one [12]. Group $3 \mathrm{MBs}$ are the deadliest of all molecular subgroups, with a 58\% 5-year OS in children and a $45 \%$ 5 -year OS in infants $[10,16,21]$. The grim outcome results from the aggregation of adverse prognostic factors, such as young age or presence of metastases (in up to $50 \%$ of patients) at diagnosis, large cell/anaplastic (LCA) histology, and $M Y C$ amplification. Group 3 is most likely to consist of multiple subcategories, out of which $M Y C$-amplified tumors confer an especially short survival; only $20 \%$ of these patients survive up to 5 years $[18,22]$. Group $3 \mathrm{MBs}$ rarely recur at the original tumor site, but reappear as metastases [23]. The rate of metastasis does not necessarily reflect survival [12]; thus, children with group 3 disease without disease spread who are assigned to be standard-risk may face undertreatment [10]. Targeted treatments are not yet developed for group 3 patients due to our limited understanding of tumorigenesis.

Group $4 \mathrm{MB}$ is the most prevalent biological subtype, comprising approximately $40 \%$ of all MB patients, predominantly between ages 3 and 16 years, and yet, its pathogenesis is the least understood $[5,10]$. Very few infants, approximately $45 \%$ of childhood and $25 \%$ of adult cases, belong to this subgroup (Fig. 1), and it is three times more frequent in males than in females across all age groups $[5,10]$. The prognosis for group 4 patients is intermediate, and the 5 -year survival reaches $80 \%$ when treated with standard therapy [13], although non-metastatic group 4 patients with chromosome 11 loss have an excellent prognosis, with $>90 \%$ survival [8]. Approximately $30-40 \%$ of group $4 \mathrm{MB}$ patients have metastases at diagnosis and are currently treated as high risk, including

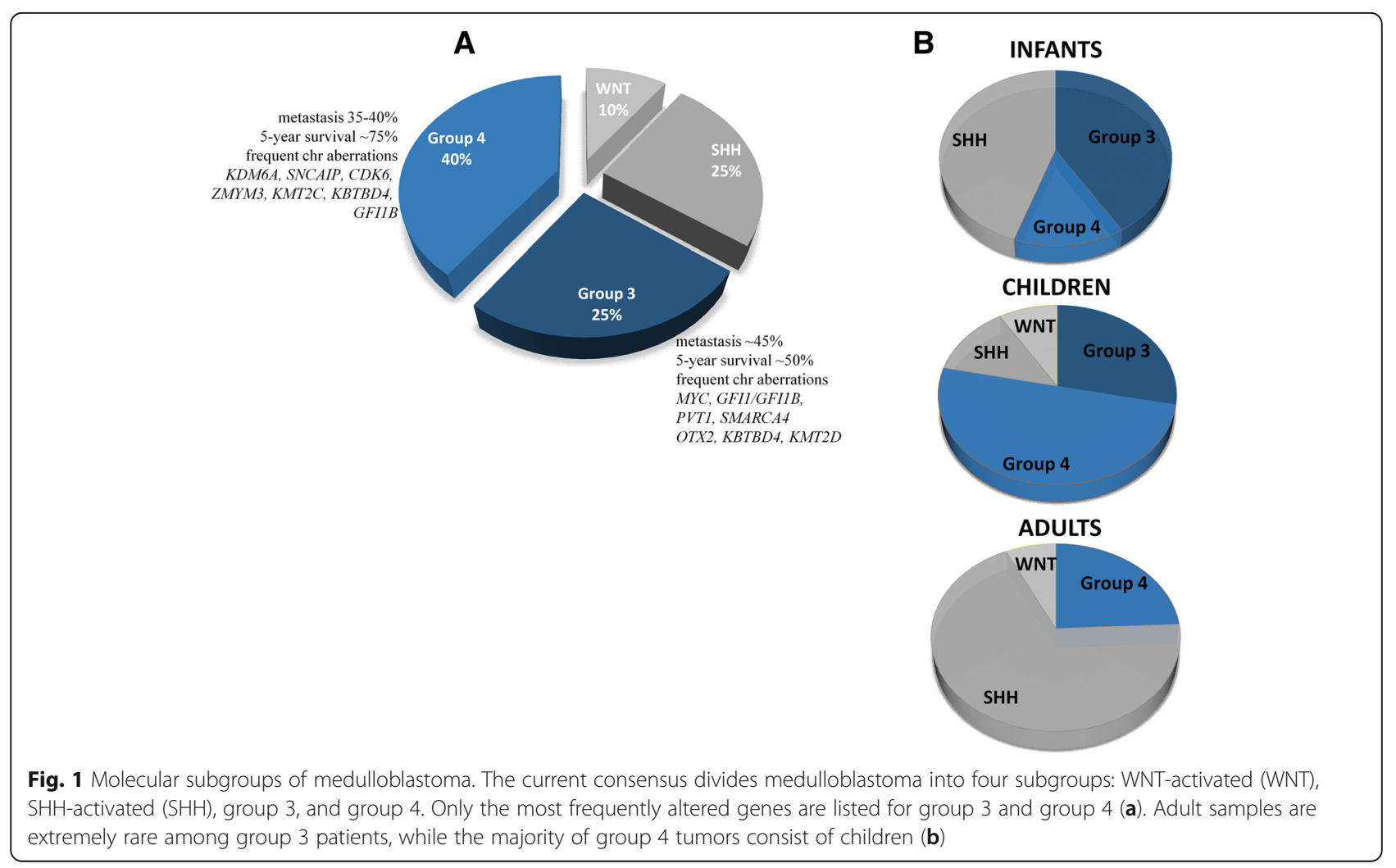


those with an LCA histology. The 5-year survival of high-risk patients is approximately $60 \%[8,10,14]$. Adults with group $4 \mathrm{MBs}$ have a significantly worse prognosis compared to the SHH- or WNT-activated subtypes [19].

\section{Molecular identification of group 3 and group 4 MBs}

The 2016 WHO classification refers to MB subgroups as genetically defined variants with prognostic value and treats group 3 and group $4 \mathrm{MBs}$ as provisional entities. The recommendation integrates histological and molecular classifications, with different prognosis for classical or LCA histology, the latter usually associated with a high-risk disease (although extremely rare in group 4) [15].

Initially, immunohistochemistry (IHC)-based markers were developed to allocate molecular subgroup identity to clinical samples. A diagnostic method involving a distinct set of antibodies (GAB1, $\beta$-catenin, filamin A, and YAP1) distinguished WNT- and SHH-activated and non-WNT/non-SHH MB subgroups in FFPE samples [24]. Another four-antibody approach to identify subgroups also from FFPE samples included DKK1 for WNT, SFRP1 for SHH, NPR3 for group 3, and KCNA1 for group 4 MBs, allocating $98 \%$ of samples into each subcategory [12]. Nevertheless, subgroup assignment solely based on IHC is not recommended any longer: patchy nuclear $\beta$-catenin accumulation might be misleading $[25,26]$ and validation studies revealed KCNA1 expression in all subgroups, making it unsuitable for classification [27]. Suboptimal reproducibility of IHC results arising from different protocols, institutional standards, and interpretations arrange for inconsistencies [25].

Identification of group 3 and group $4 \mathrm{MBs}$ should be based on either methylation or transcriptional profiling to identifying samples clustering with other tumors of the same type $[8,25]$. Transcription may be assessed by either genome-wide transcriptomics or specific gene panels, for instance, the NanoString 22 gene signature. The assay evaluates group 3 identity utilizing the expression of IMPG2, GABRA5, EGFL11, NRL, MAB21 L2, and NPR3, while allocates group 4 tumors based on KCNA1, EOMES, KHDRBS2, RBM24, UNC5D, and OASI expression [28]. The methylation- or transcriptional profiling-based classifications are robust, although their implementation might be challenging in the daily practice.

A clinically applicable rapid approach classified non-WNT/non-SHH MBs with $92 \%$ accuracy based on highly specific epigenetic biomarkers from both fresh frozen and FFPE samples. The differentially methylated CpG probes were located within an intergenic region of chromosome 12, the intronic regions of RPTOR and RIMS2, and the 3'-UTR region of VPS37B genes. The method accurately classified unambiguous group 3 and group 4 cases, however demonstrated limited discrimination capacity with tumors harboring intermediate methylation profiles [29].

\section{MBs with ambiguous subgroup identity}

A growing number of studies suggest that subgroups within non-WNT/non-SHH tumors should be explored further to capture patient diversity. A large-scale study utilizing methylomic data revealed a shared biological signature between group 3 and group 4 tumors, suggesting a likelihood of common origin. Combining the two subgroups, especially low-risk group 3 and group 4 samples for clinical purposes, results in a categorization outperforming the current risk stratification models [30] (Fig. $2 \mathrm{a}$ and 3a). Integration of methylomic and transcriptomic data found ambiguous subgroup identity in 3\% of samples [31]. Gene expression-based clustering also identified non-WNT/non-SHH subtypes with mixed signatures $[18,32]$. The ambiguity of categorization has been reflected in established MB cell lines: D283 cells have been categorized in the past as both group 3 [33] and group 4 [34] and, along with the D721 cell line, express high levels of both MYC and OTX2 mRNA. These cell lines were placed eventually to an intermediate category [35].

Three MB subgroups within non-WNT/non-SHH tumors were recently described: group 3, group 4, and intermediate group $3 / 4 \mathrm{MBs}$, the latter with remarkably good prognosis [36]. Although based on a limited sample size, the results imply that provisional group 3 and group 4 distinctions could misplace a portion of patients. The study extended the NanoString 22 gene signature [28] further, including the expression of SNCAIP, MYCC, RCVRN, and PDC genes. Future clarifications ought to standardize the methods for diagnostic purposes as patient misclassification has serious implications for treatment and enrollment into clinical trials.

\section{Molecular biology of group 3 and group 4 MBs Genetic predispositions}

Damaging germline mutations in known cancer predisposition genes is rare in non-WNT/non-SHH MB pediatric patients. In a sample of $1022 \mathrm{MBs}$, germline BRCA2 and PALB2 mutations were present in $1-2 \%$ of group 3/group 4 tumors, associated with mutational signatures typical of homologous recombination repair (HR) deficiency. Occasional heterozygous germline FANCA $(n=1$, group 3$)$ or FANCQ $(n=1$, group 4$)$ mutations were also identified and linked to an HR-deficiency mutation spectrum. Genetic testing for these patients is recommended in case of a familial history of $B R C A$-associated cancers or if mutational signatures are suggestive of HR deficiency [37]. 


\section{A Group 3}

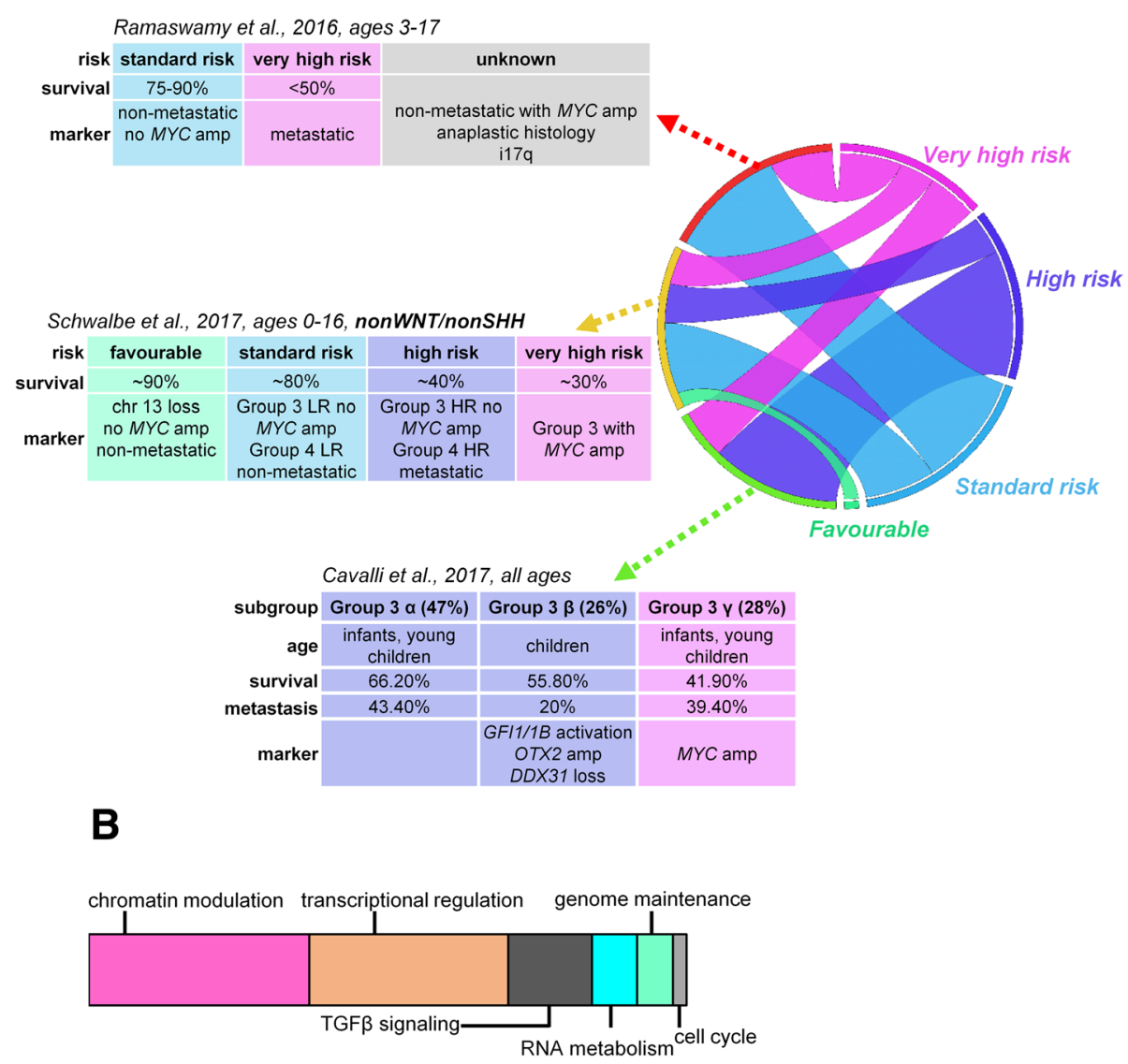

Fig. 2 Risk stratification, proposed prognostic biomarkers, and major mechanisms of tumorigenesis in group 3 medulloblastomas (a). Schematic representation of major mechanisms most frequently affected by somatic alterations within group 3 tumors contributing to medulloblastoma development (b). LR, low risk; HR, high risk

\section{Recurrent somatic driver events}

Group 3 and group 4 MBs are genetically heterogeneous and, unlike WNT and SHH-activated MBs, are not driven by well-defined, constitutively activated signaling pathways. Tetraploidy is a recurrent early genetic event in both group 3 and group $4 \mathrm{MBs}$, leading to an increased number of large-scale copy number gains [38]. A meta-analysis based on 550 samples identified a gain of $17 \mathrm{q}$ (in $58 \%$ of samples) and loss of $17 \mathrm{p}(55 \%)$ along with a loss of 16q (42\%), 10q (43\%), and 9q (21\%) and gain of 7 (39\%) and 1q (41\%) as most recurrent structural aberrations in Group 3 MBs [10] (Table 1). Tetraploidy also occurs early in approximately $40 \%$ of group 4 tumors [38], but its prognostic significance is yet unclear. Isochromosome 17q (a chromosome with two $17 \mathrm{q}$ arms) is present in about $80 \%$ of all group 4 samples but is not predictive of outcome. Chromosome 7 gain (47\%), 8p loss (41\%), 10q loss (15\%), and 11p and 18q aberrations are also regular events (Table 2). Approximately $80 \%$ of females have a complete loss of one $\mathbf{X}$ chromosome [10, 12, 18, 39]. Both group 3 and group 4 MBs harbor frequent chromosomal aberrations although somatic mutations are relatively infrequent. In fact, more than half of group 3 samples are thought to be devoided of mutations; based on deep sequencing of 92 samples, none of the 12 most significantly mutated genes were altered in group 3 and group 4 tumors [21, 40].

Somatic MYC (17\% in group 3) and $M Y C N$ (6\% in group 4) amplifications are the most frequently observed driver events [28]. The link between $M Y C$ and group 3 MB outcome is well established, and high MYC levels are associated with significantly reduced survival [18, 41]. $M Y C$ activation develops because of amplification at the MYC loci, genomic rearrangement of PVT1-MYC, or other yet-unknown mechanisms [22, 28, 42-44].

Recently, a study with a large sample size identified at least one potential driver events in $76 \%$ of group 3 and $82 \%$ of group $4 \mathrm{MBs}$, with an almost equal occurrence of $M Y C N$ amplifications across group 3 (5\%) and group 4 (6\%), with $M Y C$ amplifications restricted to group 3 


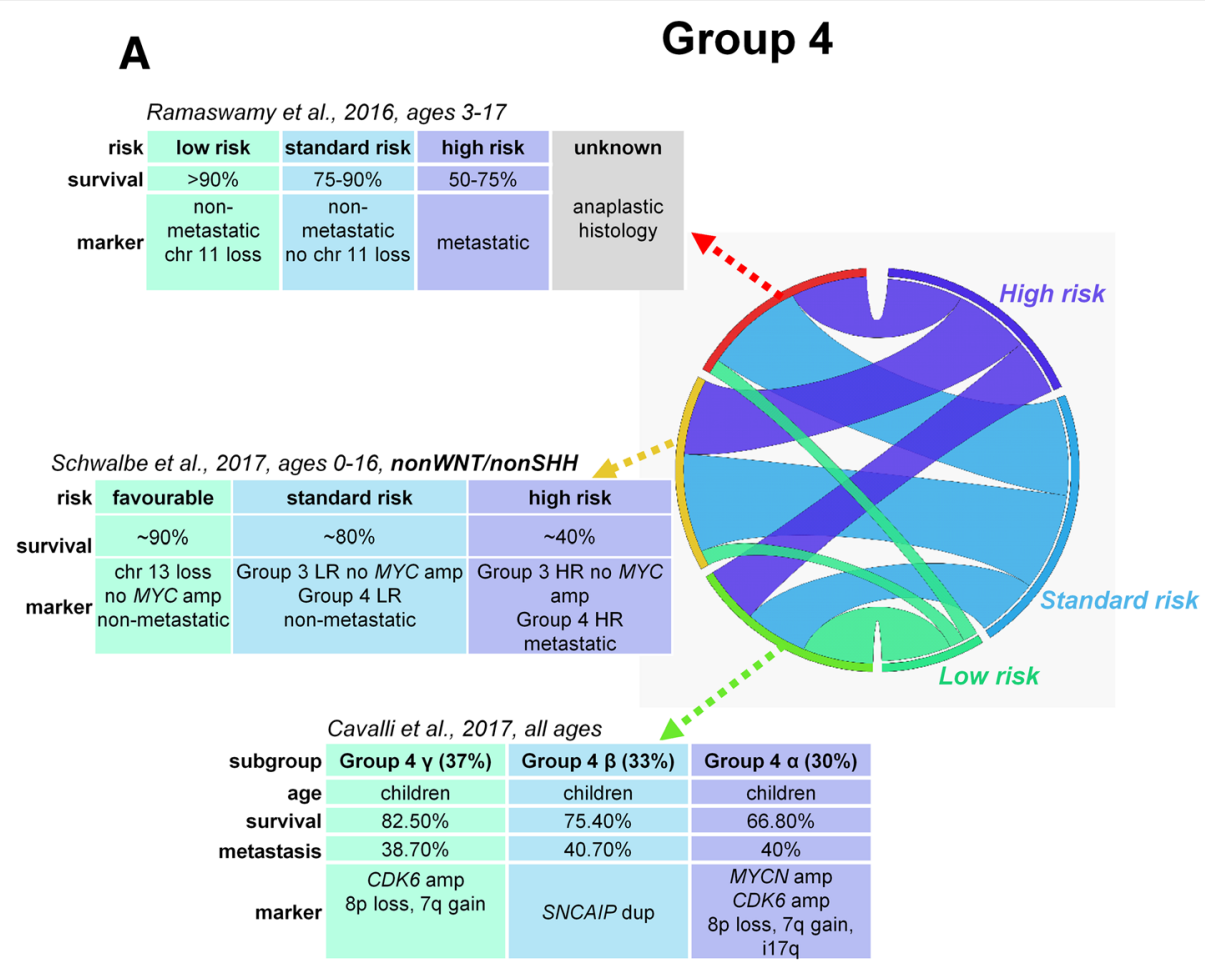

B

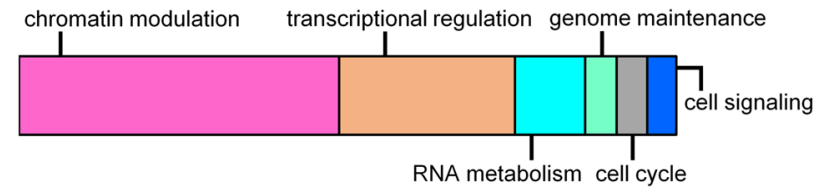

Fig. 3 Risk stratification, proposed prognostic biomarkers, and major mechanisms of tumorigenesis in group 4 medulloblastomas (a). Schematic representation of major mechanisms most frequently affected by somatic alterations within group 4 MBs contributing to medulloblastoma development (b). LR, low risk; HR, high risk

tumors (17\%) [6]. Activation of the mutually exclusive GFI1/GFIIB was identified as the most prevalent driver event through "enhancer hijacking", by depositing them near active regulatory elements. Hotspot insertions targeting a novel potential oncogene, $K B T B D 4$, were also frequent both in group 3 and group 4 samples $[6,38]$. The prognostic significance of GFI1/GFI1B activation is not yet clear [45], although a large-scale integrative analysis of gene expression and methylation data indicated the presence of GFI1/GFI1B activations mainly within a particular subtype of group 3 tumors [31].

A single copy gain of the SNCAIP gene is present in over $10 \%$ of group 4 tumors and represents the most distinctly upregulated gene within the group 4 signature. SNCAIP is involved in the development of Parkinson's disease, and its tandem duplications in group $4 \mathrm{MBs}$ are mutually exclusive with $M Y C N$ and CDK6 amplifications, the latter present in $5-10 \%$ of all group 4 tumors [18, 28]. In group $4 \mathrm{MBs}$, PRDM6, an epigenetic regulator of gene activity, is the probable target of SNCAIP-associated enhancer hijacking and is activated in about $17 \%$ of tumors [6].

SMARCA4 encoding subunits of the SWI/SNF-like chromatin-remodeling complex is among the most recurrently ( 9\%) mutated genes in group 3 tumors $[6,38]$. Network analysis of group 4 somatic copy number aberrations revealed the enrichment of genes responsible for chromatin modification and identified a novel homologous deletion of a histone-lysine demethylase, KDM6A [28], that preferentially demethylates the H3K27 trimethyl mark (H3K27me3) [46]. Somatic mutations of the KDM6A gene are exclusively present in approximately $12 \%$ of group 4 tumors, along with frequent mutations of other $6 \mathrm{KDM}$ family members (KDM1A, KDM3A, $K D M 4 A, K D M 5 A, K D M 5 B$, and $K D M 7 A)$ [21, 38, 40, 47] (Table 2). $\boldsymbol{E Z H 2}$ is also amplified or overexpressed in group 3 and 4 tumors, contributing to the inscription of H3K27me3, and is mutually exclusive with KDM6A 
Table 1 Frequent genetic alterations in group $3 \mathrm{MBs}$ according to $[6,12,28,38,40,113]$

\begin{tabular}{|c|c|c|c|c|c|}
\hline $\begin{array}{l}\text { Percentage } \\
\text { of patients }\end{array}$ & $\begin{array}{l}\text { Gene/ } \\
\text { chromosome }\end{array}$ & Modification & Gene name & $\begin{array}{l}\text { Gene } \\
\text { location }\end{array}$ & Gene function \\
\hline 58 & $17 q$ & Mainly gain & - & - & - \\
\hline 55 & $17 p$ & Mainly loss & - & - & - \\
\hline 55 & $8 q$ & Gain or loss & - & - & - \\
\hline 51 & $8 p$ & Gain or loss & - & - & - \\
\hline 48 & $7 q$ & Mainly gain & - & - & - \\
\hline 43 & $10 q$ & Mainly loss & - & - & - \\
\hline 42 & $16 q$ & Mainly loss & - & - & - \\
\hline 41 & $1 \mathrm{q}$ & Mainly gain & - & - & - \\
\hline 39 & $7 p$ & Mainly gain & - & - & - \\
\hline 38 & $13 q$ & Gain or loss & - & - & - \\
\hline 34 & $11 q$ & Mainly loss & - & - & - \\
\hline 32 & $11 p$ & Mainly loss & - & - & - \\
\hline 31 & $5 q$ & Mainly gain & - & - & - \\
\hline 30 & $5 p$ & Mainly gain & - & - & - \\
\hline 21 & $x$ & Loss & - & - & - \\
\hline 17 & MYC & $\begin{array}{l}\text { Amplification, } \\
\text { overexpression }\end{array}$ & $\begin{array}{l}\text { MYC proto-oncogene, bHLH transcription } \\
\text { factor }\end{array}$ & $8 q 24.21$ & Transcriptional regulation \\
\hline 12 & PVT1 & Amplification & Pvt1 oncogene (non-protein coding) & $8 q 24.21$ & Oncogenic IncRNA \\
\hline 11 & GFI1B & $\begin{array}{l}\text { overexpression, } \\
\text { amplification, } \\
\text { deletion }\end{array}$ & $\begin{array}{l}\text { Growth factor independent 1B transcriptional } \\
\text { repressor }\end{array}$ & $9 q 34.13$ & Transcriptional regulation \\
\hline 9 & SMARCA4 & Mutation & $\begin{array}{l}\text { SWI/SNF-related, matrix-associated, actin-dependent } \\
\text { regulator of chromatin, subfamily a, member } 4\end{array}$ & 19p13.2 & $\begin{array}{l}\text { Chromatin modulation, SWI/SNF } \\
\text { Nucleosome-remodeling complex }\end{array}$ \\
\hline 6 & KBTBD4 & Mutation & Kelch repeat and BTB domain containing 4 & $11 p 11.2$ & $\begin{array}{l}\text { Ubiquitination of target } \\
\text { substrates }\end{array}$ \\
\hline 6 & SHPRH & $\begin{array}{l}\text { Low level } \\
\text { amplification }\end{array}$ & SNF2 histone linker PHD RING helicase & $6 q 24.3$ & Genome maintenance \\
\hline 5 & CD109 & Deletion & CD109 molecule & $6 q 13$ & TGF- $\beta$ signaling \\
\hline 5 & CTDNEP1 & Mutation & CTD nuclear envelope phosphatase 1 & $17 p 13.1$ & Metabolism of fatty acids \\
\hline 5 & KMT2D & Mutation & Lysine methyltransferase 2D & $12 q 13.12$ & Chromatin modulation \\
\hline 5 & KDM7A & Mutation & Lysine demethylase 7A & $7 q 34$ & Chromatin modulation \\
\hline 5 & CHD7 & Mutation & Chromodomain helicase DNA binding protein 7 & $8 q 12.2$ & Chromatin modulation \\
\hline 5 & DDX3X & Mutation & DEAD-box helicase 3, X-linked & Xp11.4 & RNA metabolism \\
\hline 5 & KDM3A & Mutation & Lysine demethylase $3 \mathrm{~A}$ & $2 \mathrm{p} 11.2$ & Chromatin modulation \\
\hline 5 & KDM4C & Mutation & Lysine demethylase $4 C$ & $9 p 24.1$ & Chromatin modulation \\
\hline 5 & KDM5B & Mutation & Lysine demethylase $5 B$ & $1 \mathrm{q} 32.1$ & Chromatin modulation \\
\hline 5 & KDM6A & Mutation & Lysine demethylase 6A & Xp11.3 & Chromatin modulation \\
\hline 5 & MYCN & Amplification & MYCN proto-oncogene, bHLH transcription factor & $2 \mathrm{p} 24.3$ & Transcriptional regulation \\
\hline 5 & CREBBP & Amplification & CREB binding protein & $16 p 13.3$ & $\begin{array}{l}\text { Chromatin modulation, } \\
\text { transcription initiation }\end{array}$ \\
\hline 5 & DDX31 & Amplification & DEAD-box helicase 31 & $9 q 34.13$ & RNA metabolism \\
\hline 4 & ESRRG & $\begin{array}{l}\text { Low level } \\
\text { amplification }\end{array}$ & Estrogen-related receptor gamma & $1 q 41$ & $\begin{array}{l}\text { Transcriptional regulation, } \\
\text { estrogen signaling }\end{array}$ \\
\hline 4 & SNX6 & Deletion & Sorting nexin 6 & $14 q 13.1$ & TGF- $\beta$ signaling \\
\hline 4 & GFI1 & $\begin{array}{l}\text { Overexpression, } \\
\text { amplification }\end{array}$ & $\begin{array}{l}\text { Growth factor independent } 1 \text { transcriptional } \\
\text { repressor }\end{array}$ & $1 \mathrm{p} 22.1$ & Transcriptional regulation \\
\hline 3 & OTX2 & Amplification, & Orthodenticle homeobox 2 & $14 q 22.3$ & Transcriptional regulation \\
\hline
\end{tabular}


Table 1 Frequent genetic alterations in group 3 MBs according to $[6,12,28,38,40,113]$ (Continued)

\begin{tabular}{|c|c|c|c|c|c|}
\hline $\begin{array}{l}\text { Percentage } \\
\text { of patients }\end{array}$ & $\begin{array}{l}\text { Gene/ } \\
\text { chromosome }\end{array}$ & Modification & Gene name & $\begin{array}{l}\text { Gene } \\
\text { location }\end{array}$ & Gene function \\
\hline & & overexpression & & & \\
\hline 3 & FKBP1A & Deletion & FK506 binding protein $1 \mathrm{~A}$ & 20p13 & TGF- $\beta$ signaling \\
\hline 3 & CDK6 & Amplification & Cyclin-dependent kinase 6 & $7 q 21.2$ & Cell cycle \\
\hline 2 & ACVR2A & Amplification & Activin $\mathrm{A}$ receptor type $2 \mathrm{~A}$ & $\begin{array}{l}2 \mathrm{q} 22.3- \\
\mathrm{q} 23.1\end{array}$ & TGF- $\beta$ signaling \\
\hline 2 & TGFBR1 & Amplification & Transforming growth factor beta receptor 1 & $9 q 22.33$ & TGF- $\beta$ signaling \\
\hline 2 & BRCA2 & Mutation & BRCA2, DNA repair associated & $13 q 13.1$ & Genome maintenance \\
\hline 1 & ACVR2B & Amplification & Activin $\mathrm{A}$ receptor type $2 \mathrm{~B}$ & $3 p 22.2$ & TGF- $\beta$ signaling \\
\hline 1 & E2F5 & Amplification & E2F transcription factor 5 & $8 q 21.2$ & Transcriptional regulation \\
\hline- & FOXG1 & Overexpression & Forkhead box G1 & $14 q 12$ & Transcriptional regulation \\
\hline- & IMPG2 & Overexpression & Interphotoreceptor matrix proteoglycan 2 & $3 q 12.3$ & Proteoglycan \\
\hline- & GABRA5 & Overexpression & $\begin{array}{l}\text { Gamma-aminobutyric acid type A receptor alpha5 } \\
\text { subunit }\end{array}$ & $15 q 12$ & Neurotransmission \\
\hline- & EGFL11 & Overexpression & Eyes shut homolog (Drosophila) & $6 q 12$ & Cell signaling \\
\hline- & NRL & Overexpression & Neural retina leucine zipper & $\begin{array}{l}14 q 11.2- \\
q 12\end{array}$ & Transcriptional regulation \\
\hline- & MAB21L2 & Overexpression & Mab-21 like 2 & $4 q 31.3$ & $\begin{array}{l}\text { TGF- } \beta \text { signaling, neural } \\
\text { development }\end{array}$ \\
\hline- & NPR3 & Overexpression & Natriuretic peptide receptor 3 & $5 p 13.3$ & Natriuretic peptide metabolism \\
\hline
\end{tabular}

mutations. About $50 \%$ of tumors with $K D M 6 A$ and KDM1A mutations also harbor ZMYM3 mutations, suggesting a cooperation between these two genes [47]. The relatively numerous $\mathbf{C H D 7}$ or ZMYM3 mutations partake in the regulation of the $\mathrm{H} 3 \mathrm{~K} 4 \mathrm{me} 3$ mark [6]. Inactivating mutations in $M L L 2$ and $M L L 3$ genes also participate in the reduction of $\mathrm{H} 3 \mathrm{~K} 4 \mathrm{me} 3$ levels, promoting the deactivation of prodifferentiation genes [38, 48]. TBR1 and EOMES expression is significantly higher in group 3 and 4 tumors compared to other subgroups and strongly correlates with gene methylation [38]. These observations suggest that by preserving methylation marks, both group 3 and group $4 \mathrm{MBs}$ retain a stem-like epigenetic state and their pattern of gene expression is more consistent with progenitor and undifferentiated cells than cells with $\mathrm{SHH}$ and WNT-activated MBs [49]. Genes participating in chromatin remodeling, such as KDM6A and ZMYM3, are located on the $\mathrm{X}$ chromosome, explaining the higher prevalence of group 3 and group $4 \mathrm{MBs}$ in males [47]. The mutual theme of altered epigenetic regulation in tumorigenesis across group 3 and group 4 tumors (Fig. 2b and $3 \mathrm{~b}$ ) emphasizes the potential utility of drugs targeting dysregulated epigenetic modifiers, with promising in vitro results [50].

Another hallmark of non-WNT/non-SHH MBs is the elevated expression of $\boldsymbol{O T X} \mathbf{2}$, a target of TGF $\beta$ signaling. OTX2 amplification in group $3 \mathrm{MBs}$ is mutually exclusive to $M Y C$ amplification and is also routinely found in group 4 MBs $[6,28]$. OTX2 regulates cell cycle, drives proliferation, inhibits cellular differentiation, and has been associated with MB development [51]. Overexpression and knockdown of OTX2 are associated with altered expression levels of several polycomb genes (EED, SUZ12, and RBBP4) and genes encoding H3K27 demethylases (KDM6A, KDM6B, JARID2, and KDM7A) [52]. Additionally, OTX2 targets EZH2 that could be pharmacologically manipulated and is a potential target especially for patients with hematological malignancies [53]. Transcriptional profiling identified an elevated expression of a photoreceptor program in Group $3 \mathrm{MBs}$, well characterized in the retina [32]. OTX2 transactivation contributes to the regulation of transcription factors $N R L$ and $C R X$, acting as master regulators of the photoreceptor-specific program. Both genes are required for tumor maintenance while the target of $N R L$, the protein BCL-XL, is necessary for tumor cell survival. Anti-BCL therapy may serve as a rational therapeutic target in this subset of group $3 \mathrm{MBs}$ [54].

Approximately $20 \%$ of group 3 cases involve copy number alterations in TGF $\beta$ pathway genes, including the deletion of pathway inhibitors (CD109, FKBP1A, $S N X 6)$ and amplification of regulators (ACVR2A, $A C V R 2 B, T G F B R 1)$; thus, TGF $\beta$ signaling may represent a rational target for personalized therapy $[6,28]$. Notch-mediated signaling pathway plays a critical role in CNS development, stem cell maintenance, and differentiation of cerebellar granule neuron precursors; modulates epithelial-to-mesenchymal transition; and has been 
Table 2 Frequent genetic alterations in group $4 \mathrm{MBs}$ according to $[6,12,28,38,40,113]$

\begin{tabular}{|c|c|c|c|c|c|}
\hline $\begin{array}{l}\text { Percentage } \\
\text { of patients }\end{array}$ & $\begin{array}{l}\text { Gene/ } \\
\text { chromosome }\end{array}$ & Modification & Gene name & Location & Function \\
\hline 86 & $17 q$ & Mainly gain & - & - & - \\
\hline 79 & $17 p$ & Mainly loss & - & - & - \\
\hline 54 & $7 q$ & Mainly gain & - & - & - \\
\hline 50 & $8 p$ & Loss & - & - & - \\
\hline 43 & $7 p$ & Mainly gain & - & - & - \\
\hline 43 & $8 q$ & Loss & - & - & - \\
\hline 32 & $11 p$ & Loss & - & - & - \\
\hline 28 & $11 q$ & Mainly loss & - & - & - \\
\hline 21 & $x$ & Loss & - & - & - \\
\hline 17 & PRDM6 & $\begin{array}{l}\text { Amplification, } \\
\text { overexpression }\end{array}$ & PR/SET domain 6 & $5 q 23.2$ & Chromatin modulation \\
\hline 10 & SNCAIP & Tandem duplication & Synuclein alpha interacting protein & $5 q 23.2$ & Chromatin modulation \\
\hline 9 & GFI1B & $\begin{array}{l}\text { Amplification, } \\
\text { overexpression, deletion }\end{array}$ & $\begin{array}{l}\text { Growth factor independent 1B } \\
\text { transcriptional repressor }\end{array}$ & $9 q 34.13$ & Transcriptional regulation \\
\hline 8 & DDX31 & Deletion & DEAD-box helicase 31 & $9 q 34.13$ & RNA metabolism \\
\hline 8 & MYC & Amplification & $\begin{array}{l}\text { MYC proto-oncogene, bHLH } \\
\text { transcription factor }\end{array}$ & $8 q 24.21$ & Transcriptional regulation \\
\hline 8 & CHD7 & Mutation & $\begin{array}{l}\text { Chromodomain helicase DNA binding } \\
\text { protein } 7\end{array}$ & $8 q 12.2$ & Chromatin modulation \\
\hline 8 & DDX31 & Mutation & DEAD-box helicase 31 & $9 q 34.13$ & RNA metabolism \\
\hline 7 & KDM6A & Mutation & Lysine demethylase $6 \mathrm{~A}$ & Xp11.3 & Chromatin modulation \\
\hline 6 & KBTBD4 & Mutation & $\begin{array}{l}\text { Kelch repeat and BTB domain } \\
\text { containing } 4\end{array}$ & $11 p 11.2$ & Ubiquitination of target substrates \\
\hline 6 & KMT2C & Mutation & Lysine methyltransferase $2 \mathrm{C}$ & $7 q 36.1$ & Chromatin modulation \\
\hline 6 & ZMYM3 & Mutation & Zinc finger MYM-type containing 3 & Xq13.1 & Chromatin modulation \\
\hline 6 & OTX2 & Amplification & Orthodenticle homeobox 2 & $14 q 22.3$ & Transcriptional regulation \\
\hline 6 & MYCN & Amplification & $\begin{array}{l}\text { MYCN proto-oncogene, bHLH } \\
\text { transcription factor }\end{array}$ & $2 \mathrm{p} 24.3$ & Transcriptional regulation \\
\hline 5 & KDM4C & Mutation & Lysine demethylase 4C & $9 \mathrm{p} 24.1$ & Chromatin modulation \\
\hline 4 & $\mathrm{ZIC1}$ & Mutation & Zic family member 1 & $3 q 24$ & Transcriptional regulation \\
\hline 4 & CDK6 & Amplification & Cyclin-dependent kinase 6 & $7 q 21.2$ & Cell cycle \\
\hline 3 & FLG & Mutation & Filaggrin & $1 \mathrm{q} 21.3$ & Matrix protein \\
\hline 3 & KMT2D & Mutation & Lysine methyltransferase 2D & $12 q 13.12$ & Chromatin modulation \\
\hline 3 & TBR1 & Mutation & T-box, brain 1 & $2 q 24.2$ & Transcriptional regulation \\
\hline 3 & TERT & Mutation & Telomerase reverse transcriptase & $5 p 15.33$ & Genome maintenance \\
\hline 3 & GFI1 & $\begin{array}{l}\text { Amplification, } \\
\text { overexpression }\end{array}$ & $\begin{array}{l}\text { Growth factor independent } 1 \\
\text { transcriptional repressor }\end{array}$ & $1 \mathrm{p} 22.1$ & Transcriptional regulation \\
\hline 3 & CCND2 & Amplification & Cyclin D2 & $12 \mathrm{p} 13.32$ & Cell cycle \\
\hline 3 & CTNNB1 & Low level amplification & Catenin beta 1 & $3 p 22.1$ & Wingless signaling \\
\hline 3 & CTDNEP1 & Mutation & CTD nuclear envelope phosphatase 1 & 17p13.1 & Metabolism of fatty acids \\
\hline 3 & KDM1A & Mutation & Lysine demethylase $1 \mathrm{~A}$ & $1 \mathrm{p} 36.12$ & Chromatin modulation \\
\hline 3 & KDM5A & Mutation & Lysine demethylase $5 \mathrm{~A}$ & $12 \mathrm{p} 13.33$ & Chromatin modulation \\
\hline 3 & PIK3CA & Mutation & $\begin{array}{l}\text { Phosphatidylinositol-4,5-bisphosphate } \\
\text { 3-kinase } \\
\text { catalytic subunit alpha }\end{array}$ & $3 q 26.32$ & Cell signaling \\
\hline 2 & ATM & Mutation & ATM serine/threonine kinase & $11 \mathrm{q} 22.3$ & Genome maintenance \\
\hline 2 & BRCA2 & Mutation & BRCA2, DNA repair associated & $13 q 13.1$ & Genome maintenance \\
\hline
\end{tabular}


Table 2 Frequent genetic alterations in group 4 MBs according to $[6,12,28,38,40,113]$ (Continued)

\begin{tabular}{|c|c|c|c|c|c|}
\hline $\begin{array}{l}\text { Percentage } \\
\text { of patients }\end{array}$ & $\begin{array}{l}\text { Gene/ } \\
\text { chromosome }\end{array}$ & Modification & Gene name & Location & Function \\
\hline 2 & FAT1 & Mutation & FAT atypical cadherin 1 & $4 q 35.2$ & Cell signaling \\
\hline 2 & MED12 & Mutation & Mediator complex subunit 12 & Xq13.1 & Chromatin modulation \\
\hline 2 & SMARCA4 & Mutation & $\begin{array}{l}\text { SWI/SNF-related, matrix-associated, } \\
\text { actin-dependent regulator of chromatin, } \\
\text { subfamily a, member } 4\end{array}$ & 19p13.2 & $\begin{array}{l}\text { Chromatin modulation, SWI/SNF } \\
\text { nucleosome-remodeling complex }\end{array}$ \\
\hline 2 & ACVR2B & Amplification & Activin $\mathrm{A}$ receptor type $2 \mathrm{~B}$ & $3 p 22.2$ & Cell signaling \\
\hline 2 & SEMA3D & Amplification & Semaphorin 3D & $7 q 21.11$ & Axon guidance during development \\
\hline- & FOXG1 & Overexpression & Forkhead box G1 & $14 q 12$ & Transcriptional regulation \\
\hline- & KCNA1 & Overexpression & $\begin{array}{l}\text { Potassium voltage-gated channel } \\
\text { subfamily A member } 1\end{array}$ & $12 \mathrm{p} 13.32$ & Voltage-gated potassium $(\mathrm{K}+)$ channel \\
\hline- & EOMES & Overexpression & Eomesodermin & $3 p 24.1$ & Transcriptional regulation \\
\hline- & KHDRBS2 & Overexpression & $\begin{array}{l}\text { KH RNA binding domain containing, } \\
\text { signal transduction associated } 2\end{array}$ & $6 q 11.1$ & RNA metabolism \\
\hline- & RBM24 & Overexpression & RNA binding motif protein 24 & $6 p 22.3$ & RNA metabolism \\
\hline- & UNC5D & Overexpression & Unc-5 netrin receptor $D$ & $8 p 12$ & Cell adhesion, axon guidance \\
\hline- & OAS1 & Overexpression & 2'-5'-Oligoadenylate synthetase 1 & $12 q 24.2$ & Cellular innate antiviral response \\
\hline
\end{tabular}

implicated in MB disease etiology [55]. Mutations in Notch signaling genes have been described in group 3 MBs [6], with especially elevated expression of NOTCH1 in spinal metastases [56]. Somatic copy number variations in group $4 \mathrm{MBs}$ affect regulators of the NF- $\mathbf{k B}$ signaling pathway, such as deletions of NFKBIA and USP4, providing an opportunity for a rational targeted treatment [28].

We summarize the most frequent genetic aberrations of group 3 MBs in Table 1 and group 4 MBs in Table 2.

\section{Tumor proteome analysis defines novel potentially targetable signaling pathways}

Both group 3 and group $4 \mathrm{MBs}$ are characterized by abundant within-subgroup genetic heterogeneity. The low rate of recurrent lesions sets a challenge for successful therapy development. Moreover, it is difficult to infer phenotypes based on genomic data only; thus, global proteome and phosphoproteome profiles may uncover yet unknown subgroup-specific biological processes [43, 44 , 57]. A recent phosphoproteomic comparison revealed profound divergence in post-transcriptional regulation and differential kinase activity between group 3 and group 4 samples: in group 3, the PDHK, CLK, and CK2 kinase families, while in group $4 \mathrm{MBs}$, the kinases downstream of the RTK-GPCR axis were primarily enriched. The study identified aberrant RTK signaling as a unifying feature of group 4, with a potentially pivotal role of ERBB4 and SRC signaling in MB development [44]. Another tumor proteome analysis underlies the limited number of potentially targetable pathways; different transcriptional patterns from untreated $\mathrm{SHH}$, group 3 , and group $4 \mathrm{MB}$ samples converged into only two protein-signaling profiles. The first profile resembled MYC-like signaling, encompassing all of the $\mathrm{SHH}$-activated and majority of group 3 samples. The other protein profile consisted of the rest of group 3 and the bulk of group 4 tumors, displaying DNA damage/ apoptosis/neuronal signaling [58].

Elevated MYC-expression is a discriminatory feature of a subset of group 3 tumors. Some group $3 \mathrm{MBs}$ are characterized with an increased post-translational activation of MYC even in the absence of MYC amplification and are linked to the elevated expression of kinases, such as PRKDC, providing targets for future therapies [43]. HMGA1 is a stem cell phenotype regulator that targets MYC and is also targeted by MYC, and plays a role in cell growth and invasion in cancer. In a proteomic analysis, HMGA1 isoforms a and b showed elevated expression in Group $3 \mathrm{MBs}$ associated with poor outcome [57].

In summary, proteomic platforms complement cytogenetic, transcriptomic, and mutation-based data and expand translational opportunities. Data integration on multiple levels yields a more complete understanding of cancer biology for the sake of novel therapeutic strategies.

\section{Prognostic biomarkers of survival}

Within each MB subgroup, additional subtypes can be identified with distinct biological backgrounds and clinical outcomes [5, 30, 31]. Subgroup-specific markers of prognosis may present the most beneficial route to avoid over- or undertreatment [14]. The proposed four categories consist of low-, standard-, high- and very high-risk non-WNT/non-SHH MBs for non-infant (age 3-17 years) patients [25]. 
The low-risk (>90\% survival) group consists of non-metastatic group 4 patients with chromosome 11 loss (approximately one-third) and/or gain of whole chromosome 17 (approximately 5\%). The standard-risk (75-90\% survival) population includes patients with non-metastatic group 3 without $M Y C$ amplification and non-metastatic group 4 without chromosome 11 loss. The high-risk (50-75\% survival) cohort consists of metastatic group 4 patients, and very high-risk $(<50 \%$ survival) refers to metastatic group 3 patients with $M Y C$ amplification [8, 14, 59].

Risk evaluation of non-metastatic but $M Y C$-amplified group 3 tumors with an LCA histology or isochromosome i17q or group 4 MBs with anaplastic histology requires further clarifications [8] (Fig. 2a, 3a). The Medulloblastoma Advanced Genomics International Consortium identified good outcome regardless of the presence of metastases in a noteworthy portion of group $4 \mathrm{MB}$ patients with loss of chromosome 11 (15\%) and/or gain of whole chromosome 17 (5\%) [14]. Therapy de-escalation in these subtypes requires prospective clinical investigations.

\section{Emerging risk stratification models}

Based on the utilized patient populations (children vs. children and adults) and statistical methods, divergent new stratification schemes started to emerge. A recent methylation pattern-based stratification split Group 3 and Group 4 children into high-risk (HR) and low-risk (LR) categories with dramatically different survival rates (group 3, 10-year OS of $22 \%$ in HR vs. 69\% in LR; group $4,36 \%$ in HR vs. $72 \%$ in LR). Group 4 HR was characterized by frequent metastatic disease, residual disease after surgery, frequent GFI1 mutations, and high rates of i17p, compared to group 4 LR which was characterized by $M Y C N$ amplifications. Group $3 \mathrm{HR}$ was associated with frequent $M Y C$ amplification, GFI1 mutations, predominance in males, and LCA histology, while the occurrence of group $3 \mathrm{LR}$ was most frequent in infants and was associated with metastases. Shared biological signature between group 3 and group 4 tumors prompted their combination in the stratification algorithm that outperformed the current risk stratification models. In addition, a novel biomarker, loss of chromosome 13, was identified as an independent risk factor in non-WNT/non-SHH cohorts [30] (Fig. 2a and 3a).

Another methylation-based study divided group3/ group4 MBs into eight subtypes, assigning $M Y C$-driven samples to subtype II [6]. Clustering group $3 \mathrm{MBs}$ based on post-translational modifications resulted in two subtypes, out of which G3a corresponded to the earlier identified subtype II [6], representing the $M Y C$-activated group $3 \mathrm{MBs}$.
Expression- and methylation-based integrated clustering divided group 3 and group 4 tumors into six subtypes altogether; group $\mathbf{3 \alpha}$ and group $\mathbf{3} \boldsymbol{\beta}$ yielded equal survival outcomes. Group $3 \alpha$ patients were younger with frequent metastases, while group $3 \beta$ was represented by usually slightly older, non-metastatic patients with a high frequency of GFI1 and GFI1B oncogene activation, OTX2 amplification, and loss of $D D X 31$. Group $3 \gamma$ had the worst prognosis, with repeated $M Y C$ amplification and i17p enrichment [31] (Fig. 2a). Group 4a was enriched for MYCN amplification, group $4 \beta$ for SNCAIP duplications, and group $4 \gamma$ mainly for $C D K 6$ amplifications; nevertheless, the rate of metastatic spread or survival was not different across group 4 subtypes [31] (Fig. 3a).

Well-planned collaborative prospective studies will be necessary to reach a consensus among emerging risk stratification algorithms.

\section{Preclinical models of group 3 MBs reveal potential therapeutic targets}

Group 3 MBs mostly develop in the fourth ventricle as small primary tumors with early dissemination [60] and appear to originate from at least two different cell types; tumors resembling human MYC-enriched group 3 develop from cerebellar progenitors with stem-like properties after an enforced expression of $M Y C$ [61, 62] or from GABAergic neuronal progenitors [63]. $M Y C$ family genes encode transcription factors that form heterodimers to activate or repress downstream signaling. The Myc-Miz1 (a Pox virus and zinc finger (POZ) domain transcription factor) complex represses the transcription of negative cell cycle regulators [64] and activates a gene repression program responsible for maintaining a stem-like phenotype. Target genes of Myc-Miz1 are repressed in murine models of group $3 \mathrm{MBs}$, and the disruption of Myc-Miz1 inhibits group 3 tumor formation; thus, the critical interaction between Myc and Miz1 represents a defining hallmark of group $3 \mathrm{MB}$ development [65]. In the same cerebellar progenitor cells, $\mathrm{MycN}$ forms complexes with Miz1 less efficiently and induces instead sonic hedgehog-activated (SHH) MBs [65].

$M Y C$ is a poor target of small molecule inhibition; therefore, alternative strategies are necessary to target $M Y C$ transcription or $M Y C$ target genes. Spontaneous animal models recapitulating group $3 \mathrm{MB}$ development are lacking. Several orthotopic murine models of MYC-driven group 3 oncogenesis have attempted to clarify MYC involvement in MB tumor initiation, maintenance, and progression and provide models for new therapeutic strategies $[61,62,66]$. Conditional expression of $M Y C$ and loss of TRP53 in a murine model induced different tumor types in situ from various multipotent embryonic cerebellar progenitor cells [63]. 
MYC overexpression coupled with TRP53 inactivation resulted in tumors that resemble human $\mathrm{MB}$ exhibiting an LCA histology with similarity in gene expression signatures. The generated tumors were enriched for genes targeted by PI3K and $\mathbf{m T O R}$ inhibitors, indicating the importance of $P I 3 K / m T O R$ signaling in $M Y C$-driven MBs [61]. Drug screening within this model identified histone deacetylase inhibitors (HDACIs, such as LBH-589) demonstrating synergistic activity with phosphatidylinositol 3-kinase inhibitors (PI3KI) via activating the expression of the FOXO1 tumor suppressor [67]. Another murine model utilizing human neural stem and progenitor cells harboring transformed c-MYC, dominant-negative p53, and constitutively active AKT and hTERT revealed tumor sensitivity to cyclin-dependent kinase (CDK) inhibitors, such as palbociclib [66]. Based on proteomics, a subset of group 3 MBs was identified with increased post-translational activation of $M Y C$ even in the absence of $M Y C$-amplifications, with the potential role of the PRKDC kinase in promoting $M Y C$ stability. PRKDC assists DNA double-strand breaks repair through non-homologous end-joining and in $M Y C$-amplified group 3 cell lines; both $M Y C$ and $P R K D C$ protein were highly enriched. The $\boldsymbol{P R K D C}$ inhibitor NU7441 preferentially sensitized the $M Y C$-amplified cell line D458 to radiation [43].

Bromodomain and extraterminal (BET)-containing proteins facilitate gene transcription by recognizing side chain acetylated lysine on open chromatin and have been identified as novel potential targets of $M Y C$ or $M Y C N$ transcription [68]. BET bromodomain inhibitors of MYC-amplified MBs, such as compound JQ1, reduced in vitro cell proliferation and prolonged survival in MYC-amplified MB xenografts, possibly through the inhibition of BRD4 [69], a cofactor of MYC-dependent transcription [68].

Based on gene set enrichment analyses, group 3 MBs are enriched in the folate and purine metabolism pathways compared to group $4 \mathrm{MBs}$. The combined application of the folate synthesis inhibitor pemetrexed and nucleoside analog gemcitabine inhibited cellular growth in vitro and increased the survival of mice bearing cortical group 3 implants overexpressing MYC-protein. Nonetheless, resistance developed in all cases [70].

The expression of $\mathrm{GABA}_{\mathrm{A}}$ receptor $\alpha 5$ subunit gene (GABRA5) is elevated in MYC-driven group $3 \mathrm{MBs}$ [40]. Benzodiazepines function as receptor ligands of $\mathrm{GABA}_{\mathrm{A}}$ receptor $\alpha 5$ subunit, but they also have undesirable toxic side effects, such as respiratory depression in mouse xenograft models [33]. High-throughput localized intratumor drug delivery of a new benzodiazepine derivative, KRM-II-08, demonstrated higher in vivo activity compared to cisplatin in nude mouse xenografts [71].
A model investigating angiogenesis found significantly elevated VEGFA mRNA expression in Group 3 compared to the other subgroups, strongly associated with reduced overall survival. Gene enrichment analysis using the xenograft mouse models of group $3 \mathrm{MB}$ identified five potential driver genes linked to angiogenesis, of which RNH1, $S C G 2$, and AGGF1 expression were associated with decreased survival. The clinical significance of these genes requires further analysis, while VEGFA already provides a druggable target, suggesting that anti-vascularization therapies may be a potential route to treat group $3 \mathrm{MBs}$. Finally, dynamic susceptibility-weighted (DSC) MRI and susceptibility-weighted imaging (SWI) were able to identify three distinct organization patterns in the tumor vascular architecture associated with survival, thus presenting a probable clinically relevant biomarker of survival [72].

CD47 is a membrane protein that functions as an anti-phagocytic cell surface ligand that blocks macrophages from destroying tumor cells [73]. CD47 is expressed on the cell surface of malignant pediatric brain tumors [74]. CD47 binds and activates the inhibitory signal regulatory protein-a (SIRP $\alpha)$ on the cell surface. Humanized anti-CD47 antibody, Hu5F9-G4, blocked CD47-SIRPa interactions efficiently and demonstrated high therapeutic efficacy in vitro and in patient-derived xenograft models of group 3 MBs. Systemic treatment reduced the growth of both primary tumors and leptomeningeal metastases. Intraventricular administration of Hu5F9-G4 was associated with increased survival in xenograft models with metastases, although this type of drug administration was ineffective on primary tumors [74].

In summary, most preclinical in vitro and murine models resemble $M Y C$-activated MBs, and the field lacks adequate representation of heterogeneity within group 3 tumors. In fact, all of existing group $3 \mathrm{MB}$ cell lines are $M Y C$ amplified [35] compared to the presence of $M Y C$ amplifications in $17 \%$ of group 3 patients [28]. Model systems focusing on mechanisms of non-MYC-amplified group 3 tumorigenesis are in great demand.

\section{Preclinical models of group $4 \mathrm{MBs}$ are limited}

Group 3 and group 4 MBs generally develop in similar locations [63], although differences of expression patterns imply distinct cellular compartment of origin [13, 28]. A study investigating the regulatory role of predicted super-enhancers localized the expression of a master regulator exclusive to group $4 \mathrm{MBs}$ (the transcription factor $L M X 1 A$ ) in neurons of the nuclear transitory zone, possibly originating from the upper rhombic lip of the cerebellum [75]. Proteogenomic studies implicated aberrant ERBB4 and SRC signaling as hallmarks of group 4 MBs [44]. Constitutive activation of SRC along with a forced expression of a dominant negative form of 
p53 in a murine model resulted in tumors in the posterior cerebellum and dorsal hindbrain, a typical location of group $4 \mathrm{MBs}$, with a gene expression pattern similar to group 4 tumors [44]. Consistently, ERBB4 and phosphorylated SRC were detectable in the nuclear transitory zone of the murine cerebellum at embryonic day 13, but absent from granule neuron progenitors on postnatal day 7 [44]. In another murine model, the enforced expression of $M Y C N$ under the GLT1 promoter or glial fibrillary acidic protein-positive $\left(\mathrm{GFAP}^{+}\right)$neonatal cells induced $\mathrm{MB}$ development expressing KCNA1, a known marker of group 4 tumors [76].

In summary, preclinical models recapitulating group 4 MB development and progression are mostly lacking. There is only a single pair of cell lines unambiguously classified as group 4, derived from the same patient: CHLA-01-MED and CHLA-01R-MED [35]. Separate models of the mutually exclusive $M Y C N_{-}, S N C A I P_{-}$, or $C D K 6$-driven tumorigenesis are greatly needed. Preclinical systems modeling the effects of PRDM6 activation, present in $17 \%$ of group 4 patients, would promote our understanding of group 4 tumorigenesis. Given the large portion of patients $(\sim 40 \%)$ diagnosed with group $4 \mathrm{MBs}$, it is of utmost importance to identify common molecular mechanisms and therapy targets, especially for patients with high-risk disease. Integrative proteogenomic approaches might provide promising means to unravel novel targetable pathways [44].

\section{Risk-specific treatment strategies of non-WNT/ non-SHH MBs}

Medulloblastoma treatment strategy is multimodal, including maximal safe resection, radiotherapy, and chemotherapy. The treatment type and intensity are defined by age at diagnosis, metastatic status, and extent of surgical resection [77, 78]. The extent of disease determines the risk of recurrence, while patient age restricts the treatment options, as young children $(<3$ years of age) are particularly vulnerable to radiation therapy.

Patients with minimal tumor residue have a better long-term outcome, especially when metastases are absent $[78,79]$. With the help of modern imaging techniques during surgery, gross total (no remaining tumor residue) or near-total (diameter of residue is less than $1.5 \mathrm{~cm}$ ) resection is achieved in the majority of patients. When accounting for molecular subgroups, a study based on 787 patients identified a progression-free survival benefit for gross total resection over subtotal resection (tumor residue larger than $1.5 \mathrm{~cm}$ ), but no benefits in the overall survival. Improvement was most noticeable for group 4 patients, for whom gross total resection increased the progression-free survival compared to that of subtotal resection, especially in the case of metastatic disease [16]. Thus, maximum safe resection provides the best outcome without being overly aggressive by preserving the neurologic integrity, especially when the risk of neurologic morbidity is high.

Based on these factors, patients can be divided into two different treatment groups. Children older than 3 years with total or near-total resection and no metastatic dissemination are classified as average or standard risk, while patients with suboptimal tumor resection, dissemination, or metastasis and/or LCA histology are treated as having high-risk disease [77]. The LCA histology is enriched in SHH TP53 mutant and high-risk group 3 tumors and is associated with a poor outcome across all age groups, with a 5-year overall survival (OS) as low as $22 \%$ in infants [10]. Risk stratification also determines the intensity of craniospinal irradiation [80]. The average risk, non-infant patients are treated with $23.4 \mathrm{~Gy}$ craniospinal irradiation with a boost of 55 Gy to the tumor bed in the posterior fossa, followed by adjuvant chemotherapy [81]. High-risk patients receive a dose of 36-39 Gy, a boost of $55 \mathrm{~Gy}$ to the tumor bed, and adjuvant chemotherapy [82]. Typical chemotherapy regimens consist of cisplatin/carboplatin-vincristine-cyclophosphamide combinations. A prospective study of average-risk group 4 patients aged 3-17 years treated with surgery, irradiation, and chemotherapy found excellent 5-year progression-free survival (95.9\% and $88.7 \%$ ) for patients treated by two different protocols [17].

Infants under the age of 3 years require delayed radiation therapy and are preferably treated by multiagent chemotherapy. The tested chemotherapy regimens include vincristine, cyclophosphamide, etoposide, and cisplatin followed by autologous hematopoietic cell rescue (CCG-99703) and methotrexate (intravenous and intraventricular), vincristine, cyclophosphamide, and carboplatin (HIT-SKK'92) [83, 84]. This approach provides a better outcome for children with gross total resection with an absence of metastatic dissemination compared to patients with residual or metastatic disease [84-86]. Delay of radiation therapy may be particularly favorable in young children with an $\mathrm{MB}$ of desmoplastic/extensive nodular histology; thus, the advantage of deferred radiotherapy is histological subtype-specific as well [87]. Furthermore, radiation avoidance in infants reduces treatment-related neurocognitive deficits [88].

In adults, due to the relatively low incidence of MBs ( $<1 \%$ of all adult CNS tumors), there is no accepted standard of care. The current treatment strategy involves craniospinal irradiation given mostly post-resection as well as occasional chemotherapy mainly for high-risk disease, both with unknown outcomes $[89,90]$.

The clinicopathologic feature-based risk stratification fails to consider heterogeneity within standard- and high-risk patients. Nonetheless, an exciting transformation is ongoing with the integration of molecular data 
into MB classification [15]. Ongoing clinical trials investigate the optimal clinical and molecular risk-directed therapy in a subtype-specific manner in non-WNT/ non-SHH MBs, although rational targeted approaches are still absent in existing trials. A phase II trial NCT01878617 with a primary completion date of 2023 contains a treatment arm that investigates the value of new chemotherapy agents (pemetrexed and gemcitabine) supplemented to standard treatment in intermediateand high-risk patients and the effects of reduced-dose cyclophosphamide as first line in standard risk of non-WNT/non-SHH MBs.

Therapy optimization awaits solutions for a number of ongoing challenges. High-risk MBs have been a neglected entity in international clinical trials. It is of top priority especially for very high-risk patients (such as group 3 with $M Y C$ amplifications) to clinically evaluate substances previously determined as effective in preclinical studies, such as histone deacetylases and PI3K inhibitors. Therapies are also in demand for metastatic patients. Moreover, prospective studies are required to validate the clinical utility of low-risk biomarkers, particularly in metastatic tumors, and clinical trials are needed to test therapy de-escalation in low-risk populations.

\section{Metastatic non-WNT/non-SHH medulloblastomas}

MBs have the tendency to disseminate early via the cerebrospinal fluid (CSF) in the leptomeningeal space in three biologically distinct forms: free-floating tumor cells in the CSF, nodular and laminar metastases, and the last with the shortest survival [91]. About $45 \%$ of group 3 and $40 \%$ of group 4 patients have disease dissemination at the time of diagnosis, frequently at distant locations, and dissemination is independent of the type of therapy [23]. Group 3 metastases are mostly laminar compared to the more nodular pattern in metastatic group 4 patients, and suprasellar metastases are highly specific to group $4 \mathrm{MBs}$, suggesting different molecular mechanisms of disease spread across subtypes [92]. Disease dissemination occurs in the central nervous system in half of the patients, and extraneural metastases (ENMs) are located frequently in the bone $(84 \%)$, bone marrow (27\%), lymph nodes (15\%), and liver and lung (6-6\%) [93]. Metastatic patients are treated for a high-risk disease, but most patients experience relapse and disease spread regardless of therapy. The prognosis is particularly poor for group 3 patients with $M Y C$ or $M Y C N$ amplifications; nevertheless, not all group 3 metastatic patients have a uniformly poor outcome [94].

The outlook for previously irradiated patients with $\mathrm{MB}$ recurrence is grim in spite of the multitude of treatment options including surgery, radiation, high-dose chemotherapy, and participation in clinical trials [95-97].
Overall, relapse is responsible for $95 \%$ of $\mathrm{MB}$-associated deaths, emphasizing the need for more competent therapies [3]. To prevent disease spread and recurrence, we must understand the molecular mechanisms regulating migration and invasion better.

Targetable somatic mutations, assessed by multiregional biopsies, are spatially heterogeneous even within primary tumors [98]. Even though metastases maintain the subgroup identity of their corresponding primary lesions, primary tumors and metastatic clones are substantially different as a consequence of clonal selection. Nevertheless, the preserved subgroup identity suggests a different cellular origin across group 3 and group $4 \mathrm{MBs}$ [99-101].

Molecular pathways involved in self-renewal and metastases are starting to emerge. Notch signaling has been linked to medulloblastoma development [55], with a particular focus on NOTCH1 driving group $3 \mathrm{MB}$ metastases [56]. Spinal metastases expressed higher levels of $\mathrm{NOTCH} 1$ and Notch1 pathway-regulated genes (including genes responsible for motility, migration, and adhesion, such as TWIST1) compared to primary tumor sites, suggesting a distinct population of $\mathrm{MB}$ cells that are able to metastasize. $\mathrm{NOTCH}^{+}$cells also represent a population of stem cells implicated in self-renewal and maintenance of the primary tumors. Mice bearing group $3 \mathrm{MBs}$ developed lower rates of spinal metastases after treatment with a NOTCH1-blocking antibody anti-NRR1, supporting the importance of the Notch1 pathway as a therapy target [56]. $\boldsymbol{B M I 1}$ has been implicated in MB pathogenesis and poor outcome [102] and is a direct downstream target of NOTCH1 and TWIST. NOTCH1 silencing downregulated MYC expression, while silencing TWIST1 resulted in $M Y C$ levels comparable with controls, suggesting different regulatory models of NOTCH1-MYC and NOTCH1-TWIST1-BMI1 axes [56].

Overexpression of PRUNE1 promotes motility and metastatic processes in solid tumors and is associated with poor survival [103, 104]. Protein products of PRUNE1 and NME1 are preferentially expressed during brain development [105] and form a protein complex [106]. In metastatic group 3, MBs PRUNE1 enhanced TGF $\beta$ signaling through the upregulation of OTX2 and SNAIL and suppression of PTEN, and induced epithelial-to-mesenchymal transition [107]. Disrupting the interaction between PRUNE1 and NME1 with a competitive permeable peptide in orthotropic xenografts inhibited primary tumor growth and cancer spread; moreover, a small molecule PRUNE1 inhibitor, AA7.1, impaired $\mathrm{MB}$ progression and dissemination in xenografts [107]. MBs and leptomeningeal metastases contain abundant and activated IGF1R, IGF1, and IGF2 compared to normal cerebellar tissue [108], promoting survival and proliferation of granule neuron precursors 
[109]. In MYC-amplified MB cells, IGF1 induces migration; thus, the bioavailability of IGF1 from the leptomeningeal surface may promote migration and metastatic growth. Targeting IGF1R may represent a feasible approach to prevent spread within high-risk MBs [110]. Upregulated PDGFRA and downstream members of the RAS/MAPK signaling pathways have also been identified in metastases, associated with in vitro migratory behavior [111].

Preclinical models of anti-metastatic treatment are scarce. In a recent study, humanized anti-CD47 antibody, Hu5F9-G4, blocked CD47-SIRP $\alpha$ interactions that halt macrophages from destroying tumor cells. Systemic Hu5F9-G4 administration reduced the growth of both primary tumors and leptomeningeal metastases in Group $3 \mathrm{MB}$ xenografts [74]. Intraventricular drug administration increased survival in xenografts with metastases, although it was ineffective on primary tumors. Additionally, Hu5F9-G4 eliminated CD15+ tumor-initiating cells significantly, suggesting to be a potential treatment against stem cells to prevent relapses [74].

Collection of clinical samples from primary lesions and metastases would facilitate the exploration of functional heterogeneity within primary tumors and targetable signaling pathways in metastases, albeit group 3 and group 4 MBs usually relapse as metastases, making the resampling difficult. Despite emerging molecular mechanisms of self-renewal and disease spread, clinically relevant substances targeting metastases are just starting to emerge. Eliminating treatment-resistant stem-like cells could provide a feasible approach to treat high-risk MBs in the future [112], although cell populations responsible for treatment resistance are not fully explored.

\section{Conclusions}

Molecular synthesis suggests that despite tumor heterogeneity, rare molecular events converge on a limited number of potentially targetable signaling pathways, and the dysregulated epigenetic machinery offers rational targets for drug development across subgroups.

Current preclinical models explore only a thin layer of phenotypes in high-risk tumors ( $M Y C$ - or $M Y C N$-amplified group $3 \mathrm{MBs}$ ), but additional models are needed to analyze mechanisms of tumorigenesis. Samples from relapses compared to primary tumors would also provide a wealth of information, but recurrent MBs are rarely resected.

Nonetheless, unknown territories are still abundant, especially within non-WNT/non-SHH tumors. Molecular stratification is not conclusive, as intermediate subgroups are emerging. Reliable methods, accessible for daily clinical application, are sought after to assess subgroup (and subtype) affiliation, as the correct classification of patients is needed to bring a revolution in systemic treatment. Molecularly stratified treatment options are limited, and targeted therapies are only in preclinical development. The development of rational treatment approaches especially for high-risk and metastatic non-WNT/non-SHH patients is of first priority to suppress stagnant survival rates of the past decades.

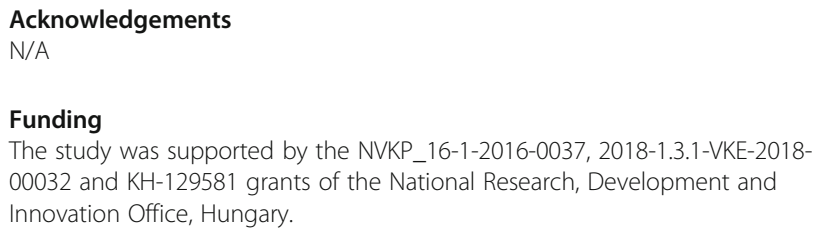

Availability of data and materials

Data sharing is not applicable to this article as no datasets were generated or analysed during the current study.

\section{Authors' contributions}

OM studied the concept and design and drafted and reviewed the manuscript for intellectual content. FG studied the concept and design and reviewed the manuscript. BG studied the concept and design and drafted and reviewed the manuscript for intellectual content. All authors read and approved the final manuscript.

\section{Ethics approval and consent to participate \\ N/A}

Consent for publication

All coauthors have reviewed and approved the contents of the manuscript.

Competing interests

The authors declare that they have no competing of interest.

\section{Publisher's Note}

Springer Nature remains neutral with regard to jurisdictional claims in published maps and institutional affiliations.

\section{Author details}

12nd Department of Pediatrics, Semmelweis University, Tüzoltó u. 7-9, Budapest H-1094, Hungary. ${ }^{2}$ MTA TTK Lendület Cancer Biomarker Research Group, Institute of Enzymology, Hungarian Academy of Sciences, Magyar tudósok körútja 2, Budapest H-1117, Hungary. ${ }^{3}$ Department of Radiological, Oncological, and Anatomo-Pathological Sciences, University Sapienza of Rome, Rome, Italy. ${ }^{4}$ IRCCS Neuromed, Pozzilli (Is), Italy.

Received: 30 November 2018 Accepted: 26 February 2019

Published online: 15 March 2019

References

1. Smoll NR. Relative survival of childhood and adult medulloblastomas and primitive neuroectodermal tumors (PNETs). Cancer. 2012;118(5):1313-22.

2. Ward E, DeSantis C, Robbins A, Kohler B, Jemal A. Childhood and adolescent cancer statistics, 2014. CA Cancer J Clin. 2014:64(2):83-103.

3. Pizer BL, Clifford SC. The potential impact of tumour biology on improved clinical practice for medulloblastoma: progress towards biologically driven clinical trials. Br J Neurosurg. 2009;23(4):364-75.

4. Pui CH, Gajjar AJ, Kane JR, Qaddoumi IA, Pappo AS. Challenging issues in pediatric oncology. Nat Rev Clin Oncol. 2011;8(9):540-9.

5. Northcott PA, Korshunov A, Pfister SM, Taylor MD. The clinical implications of medulloblastoma subgroups. Nat Rev Neurol. 2012;8(6):340-51.

6. Northcott PA, Buchhalter I, Morrissy AS, Hovestadt V, Weischenfeldt J, Ehrenberger $\mathrm{T}$, et al. The whole-genome landscape of medulloblastoma subtypes. Nature. 2017;547(7663):311-7. 
7. Gajjar AJ, Robinson GW. Medulloblastoma-translating discoveries from the bench to the bedside. Nat Rev Clin Oncol. 2014;11(12):714-22.

8. Ramaswamy V, Remke M, Bouffet E, Bailey S, Clifford SC, Doz F, et al. Risk stratification of childhood medulloblastoma in the molecular era: the current consensus. Acta Neuropathol. 2016;131(6):821-31.

9. Schwalbe EC, Williamson D, Lindsey JC, Hamilton D, Ryan SL, Megahed H, et al. DNA methylation profiling of medulloblastoma allows robust subclassification and improved outcome prediction using formalin-fixed biopsies. Acta Neuropathol. 2013;125(3):359-71.

10. Kool M, Korshunov A, Remke M, Jones DT, Schlanstein M, Northcott PA, et al. Molecular subgroups of medulloblastoma: an international meta-analysis of transcriptome, genetic aberrations, and clinical data of WNT, SHH, group 3, and group 4 medulloblastomas. Acta Neuropathol. 2012;123(4):473-84.

11. Ellison DW, Kocak M, Dalton J, Megahed H, Lusher ME, Ryan SL, et al. Definition of disease-risk stratification groups in childhood medulloblastoma using combined clinical, pathologic, and molecular variables. J Clin Oncol. 2011;29(11):1400-7.

12. Northcott PA, Hielscher T, Dubuc A, Mack S, Shih D, Remke M, et al. Pediatric and adult sonic hedgehog medulloblastomas are clinically and molecularly distinct. Acta Neuropathol. 2011;122(2):231-40.

13. Taylor MD, Northcott PA, Korshunov A, Remke M, Cho YJ, Clifford SC, et al. Molecular subgroups of medulloblastoma: the current consensus. Acta Neuropathol. 2012;123(4):465-72.

14. Shih DJ, Northcott PA, Remke M, Korshunov A, Ramaswamy V, Kool M, et al. Cytogenetic prognostication within medulloblastoma subgroups. J Clin Oncol. 2014;32(9):886-96.

15. Louis DN, Perry A, Reifenberger G, von Deimling A, Figarella-Branger D, Cavenee WK, et al. The 2016 World Health Organization classification of tumors of the central nervous system: a summary. Acta Neuropathol. 2016; 131(6):803-20.

16. Thompson EM, Hielscher T, Bouffet E, Remke M, Luu B, Gururangan S, et al. Prognostic value of medulloblastoma extent of resection after accounting for molecular subgroup: a retrospective integrated clinical and molecular analysis. The Lancet Oncology. 2016;17(4):484-95.

17. Ramaswamy V, Remke M, Adamski J, Bartels U, Tabori U, Wang X, et al. Medulloblastoma subgroup-specific outcomes in irradiated children: who are the true high-risk patients? Neuro-oncology. 2016;18(2):291-7.

18. Cho YJ, Tsherniak A, Tamayo P, Santagata S, Ligon A, Greulich H, et al. Integrative genomic analysis of medulloblastoma identifies a molecular subgroup that drives poor clinical outcome. J Clin Oncol. 2011;29(11):1424-30.

19. Zhao F, Ohgaki H, Xu L, Giangaspero F, Li C, Li P, et al. Molecular subgroups of adult medulloblastoma: a long-term single-institution study. Neurooncology. 2016;18(7):982-90.

20. Remke M, Hielscher T, Northcott PA, Witt H, Ryzhova M, Wittmann A, et al. Adult medulloblastoma comprises three major molecular variants. J Clin Oncol. 2011;29(19):2717-23.

21. Northcott PA, Jones DT, Kool M, Robinson GW, Gilbertson RJ, Cho YJ, et al. Medulloblastomics: the end of the beginning. Nat Rev Cancer. 2012;12(12): 818-34

22. Tamayo P, Cho YJ, Tsherniak A, Greulich H, Ambrogio L, Schouten-van Meeteren $\mathrm{N}$, et al. Predicting relapse in patients with medulloblastoma by integrating evidence from clinical and genomic features. J Clin Oncol. 2011; 29(11):1415-23.

23. Ramaswamy V, Remke M, Bouffet E, Faria CC, Perreault S, Cho YJ, et al. Recurrence patterns across medulloblastoma subgroups: an integrated clinical and molecular analysis. The Lancet Oncology. 2013; 14(12):1200-7.

24. Ellison DW, Dalton J, Kocak M, Nicholson SL, Fraga C, Neale G, et al. Medulloblastoma: clinicopathological correlates of $\mathrm{SHH}, \mathrm{WNT}$, and non-SHH/ WNT molecular subgroups. Acta Neuropathol. 2011;121(3):381-96.

25. Gottardo NG, Hansford JR, McGlade JP, Alvaro F, Ashley DM, Bailey S, et al. Medulloblastoma down under 2013: a report from the third annual meeting of the international Medulloblastoma Working Group. Acta Neuropathol. 2014;127(2):189-201.

26. Goschzik T, Zur Muhlen A, Kristiansen G, Haberler C, Stefanits H, Friedrich C, et al. Molecular stratification of medulloblastoma: comparison of histological and genetic methods to detect Wnt activated tumours. Neuropathol Appl Neurobiol. 2015;41(2):135-44.

27. Min HS, Lee JY, Kim S-K, Park S-H. Genetic grouping of medulloblastomas by representative markers in pathologic diagnosis. Transl Oncol. 2013;6(3): 265-72.
28. Northcott PA, Shih DJ, Remke M, Cho YJ, Kool M, Hawkins C, et al. Rapid, reliable, and reproducible molecular sub-grouping of clinical medulloblastoma samples. Acta Neuropathol. 2012;123(4):615-26.

29. Gómez S, Garrido-Garcia A, Garcia-Gerique L, Lemos I, Suñol M, de Torres C, et al. A novel method for rapid molecular subgrouping of medulloblastoma. Clin Cancer Res. 2018;24(6):1355-63.

30. Schwalbe EC, Lindsey JC, Nakjang S, Crosier S, Smith AJ, Hicks D, et al. Novel molecular subgroups for clinical classification and outcome prediction in childhood medulloblastoma: a cohort study. The Lancet Oncology. 2017; 18(7):958-71.

31. Cavalli FMG, Remke M, Rampasek L, Peacock J, Shih DJH, Luu B, et al. Intertumoral heterogeneity within medulloblastoma subgroups. Cancer cell. 2017:31(6):737-54.e6.

32. Kool M, Koster J, Bunt J, Hasselt NE, Lakeman A, van Sluis P, et al. Integrated genomics identifies five medulloblastoma subtypes with distinct genetic profiles, pathway signatures and clinicopathological features. PLoS One. 2008:3(8):e3088

33. Sengupta S, Weeraratne SD, Sun H, Phallen J, Rallapalli SK, Teider N, et al. alpha5-GABAA receptors negatively regulate MYC-amplified medulloblastoma growth. Acta Neuropathol. 2014;127(4):593-603.

34. Snuderl M, Batista A, Kirkpatrick ND, de Almodovar CR, Riedemann L, Walsh EC, et al. Targeting placental growth factor/neuropilin 1 pathway inhibits growth and spread of medulloblastoma. Cell. 2013;152(5):1065-76.

35. Ivanov DP, Coyle B, Walker DA, Grabowska AM. In vitro models of medulloblastoma: choosing the right tool for the job. J Biotechnol. 2016; 236:10-25.

36. Lastowska M, Trubicka J, Niemira M, Paczkowska-Abdulsalam M, KarkucinskaWieckowska A, Kaleta M, et al. Medulloblastoma with transitional features between group 3 and group 4 is associated with good prognosis. J NeuroOncol. 2018;138(2):231-40.

37. Waszak SM, Northcott PA, Buchhalter I, Robinson GW, Sutter C, Groebner S, et al. Spectrum and prevalence of genetic predisposition in medulloblastoma: a retrospective genetic study and prospective validation in a clinical trial cohort. The Lancet Oncology. 2018;19(6):785-98.

38. Jones DT, Jager N, Kool M, Zichner T, Hutter B, Sultan M, et al. Dissecting the genomic complexity underlying medulloblastoma. Nature. 2012; 488(7409):100-5.

39. Remke $M$, Hielscher $T$, Korshunov A, Northcott PA, Bender $\mathrm{S}$, Kool $M$, et al. FSTL5 is a marker of poor prognosis in non-WNT/non-SHH medulloblastoma. J Clin Oncol. 2011:29(29):3852-61.

40. Pugh TJ, Weeraratne SD, Archer TC, Pomeranz Krummel DA, Auclair D, Bochicchio J, et al. Medulloblastoma exome sequencing uncovers subtypespecific somatic mutations. Nature. 2012;488(7409):106-10.

41. Grotzer MA, Hogarty MD, Janss AJ, Liu X, Zhao H, Eggert A, et al. MYC messenger RNA expression predicts survival outcome in childhood primitive neuroectodermal tumor/medulloblastoma. Clin Cancer Res. 2001;7(8):2425-33.

42. Ryan SL, Schwalbe EC, Cole M, Lu Y, Lusher ME, Megahed H, et al. MYC family amplification and clinical risk-factors interact to predict an extremely poor prognosis in childhood medulloblastoma. Acta Neuropathol. 2012 123(4):501-13

43. Archer TC, Ehrenberger T, Mundt F, Gold MP, Krug K, Mah CK, et al. Proteomics, post-translational modifications, and integrative analyses reveal molecular heterogeneity within medulloblastoma subgroups. Cancer cell. 2018;34(3):396-410.e8

44. Forget A, Martignetti L, Puget S, Calzone L, Brabetz S, Picard D, et al. Aberrant ERBB4-SRC signaling as a hallmark of group 4 medulloblastoma revealed by integrative phosphoproteomic profiling. Cancer cell. 2018;34(3): 379-95.e7.

45. Northcott PA, Lee C, Zichner T, Stutz AM, Erkek S, Kawauchi D, et al. Enhancer hijacking activates GFI1 family oncogenes in medulloblastoma. Nature. 2014;511(7510):428-34.

46. Agger K, Cloos PA, Christensen J, Pasini D, Rose S, Rappsilber J, et al. UTX and JMJD3 are histone H3K27 demethylases involved in HOX gene regulation and development. Nature. 2007:449(7163):731-4.

47. Robinson G, Parker M, Kranenburg TA, Lu C, Chen X, Ding L, et al. Nove mutations target distinct subgroups of medulloblastoma. Nature. 2012; 488(7409):43-8.

48. Dubuc AM, Remke M, Korshunov A, Northcott PA, Zhan SH, Mendez-Lago $M$, et al. Aberrant patterns of H3K4 and H3K27 histone lysine methylation occur across subgroups in medulloblastoma. Acta Neuropathol. 2013;125(3): 373-84. 
49. Dubuc AM, Mack S, Unterberger A, Northcott PA, Taylor MD. The epigenetics of brain tumors. Methods in molecular biology (Clifton, NJ). 2012;863:139-53

50. Wang K, Shrestha R, Wyatt AW, Reddy A, Lehar J, Wang Y, et al. A metaanalysis approach for characterizing pan-cancer mechanisms of drug sensitivity in cell lines. PLoS One. 2014;9(7):e103050.

51. Bunt J, Hasselt NE, Zwijnenburg DA, Hamdi M, Koster J, Versteeg R, et al. OTX2 directly activates cell cycle genes and inhibits differentiation in medulloblastoma cells. Int J Cancer. 2012;131(2):E21-32.

52. Bunt J, Hasselt NA, Zwijnenburg DA, Koster J, Versteeg R, Kool M. OTX2 sustains a bivalent-like state of OTX2-bound promoters in medulloblastoma by maintaining their H3K27me3 levels. Acta Neuropathol. 2013;125(3):385-94.

53. McCabe MT, Creasy CL. EZH2 as a potential target in cancer therapy. Epigenomics. 2014;6(3):341-51.

54. Garancher A, Lin CY, Morabito M, Richer W, Rocques N, Larcher M, et al. NRL and CRX define photoreceptor identity and reveal subgroup-specific dependencies in medulloblastoma. Cancer cell. 2018:33(3):435-49.e6.

55. Fan X, Mikolaenko I, Elhassan I, Ni X, Wang Y, Ball D, et al. Notch1 and notch2 have opposite effects on embryonal brain tumor growth. Cance Res. 2004;64(21):7787-93.

56. Kahn SA, Wang X, Nitta RT, Gholamin S, Theruvath J, Hutter G, et al. Notch1 regulates the initiation of metastasis and self-renewal of Group 3 medulloblastoma. Nature communications. 2018;9(1):4121.

57. Rivero-Hinojosa S, Lau LS, Stampar M, Staal J, Zhang H, Gordish-Dressman H, et al. Proteomic analysis of medulloblastoma reveals functional biology with translational potential. Acta neuropathologica communications. 2018;6(1):48.

58. Zomerman WW, Plasschaert SLA, Conroy S, Scherpen FJ, Meeuwsen-de Boer TGJ, Lourens HJ, et al. Identification of two protein-signaling states delineating transcriptionally heterogeneous human medulloblastoma. Cell Rep. 2018;22(12):3206-16.

59. Zhukova N, Ramaswamy V, Remke M, Pfaff E, Shih DJ, Martin DC, et al. Subgroup-specific prognostic implications of TP53 mutation in medulloblastoma. J Clin Oncol. 2013;31(23):2927-35.

60. Raybaud C, Ramaswamy V, Taylor MD, Laughlin S. Posterior fossa tumors in children: developmental anatomy and diagnostic imaging. Child's nervous system: ChNS: official journal of the International Society for Pediatric Neurosurgery. 2015;31(10):1661-76.

61. Pei Y, Moore CE, Wang J, Tewari AK, Eroshkin A, Cho YJ, et al. An animal model of MYC-driven medulloblastoma. Cancer Cell. 2012;21(2):155-67.

62. Kawauchi D, Robinson G, Uziel T, Gibson P, Rehg J, Gao C, et al. A mouse model of the most aggressive subgroup of human medulloblastoma. Cancer Cell. 2012;21(2):168-80.

63. Kawauchi D, Ogg RJ, Liu L, Shih DJH, Finkelstein D, Murphy BL, et al. Novel MYC-driven medulloblastoma models from multiple embryonic cerebellar cells. Oncogene. 2017;36(37):5231-42.

64. Staller P, Peukert K, Kiermaier A, Seoane J, Lukas J, Karsunky H, et al. Repression of p15INK4b expression by Myc through association with Miz-1. Nat Cell Biol. 2001;3(4):392-9.

65. Vo BT, Wolf E, Kawauchi D, Gebhardt A, Rehg JE, Finkelstein D, et al. The interaction of Myc with Miz1 defines medulloblastoma subgroup identity. Cancer Cell. 2016;29(1):5-16.

66. Hanaford AR, Archer TC, Price A, Kahlert UD, Maciaczyk J, Nikkhah G, et al. DiSCoVERing innovative therapies for rare tumors: combining genetically accurate disease models with in silico analysis to identify novel therapeutic targets. Clinical cancer research: an official journal of the American Association for Cancer Research. 2016;22(15):3903-14.

67. Pei Y, Liu KW, Wang J, Garancher A, Tao R, Esparza LA, et al. HDAC and PI3K antagonists cooperate to inhibit growth of MYC-driven medulloblastoma. Cancer Cell. 2016:29(3):311-23.

68. Delmore JE, Issa GC, Lemieux ME, Rahl PB, Shi J, Jacobs HM, et al. BET bromodomain inhibition as a therapeutic strategy to target c-Myc. Cell. 2011;146(6):904-17.

69. Bandopadhayay P, Bergthold G, Nguyen B, Schubert S, Gholamin S, Tang Y, et al. BET-bromodomain inhibition of MYC-amplified medulloblastoma. Clinical cancer research : an official journal of the American Association for Cancer Research. 2014;20(4):912-25.

70. Morfouace M, Shelat A, Jacus M, Freeman BB 3rd, Turner D, Robinson S, et al. Pemetrexed and gemcitabine as combination therapy for the treatment of Group3 medulloblastoma. Cancer Cell. 2014;25(4):516-29.

71. Jonas O, Calligaris D, Methuku KR, Poe MM, Francois JP, Tranghese F, et al. First in vivo testing of compounds targeting group 3 medulloblastomas using an implantable microdevice as a new paradigm for drug development. J Biomed Nanotechnol. 2016;12(6):1297-302.

72. Thompson EM, Keir ST, Venkatraman T, Lascola C, Yeom KW, Nixon AB, et al. The role of angiogenesis in group 3 medulloblastoma pathogenesis and survival. Neuro-oncology. 2017;19(9):1217-27.

73. Jaiswal $\mathrm{S}$, Jamieson $\mathrm{CH}$, Pang WW, Park CY, Chao MP, Majeti R, et al. CD47 is upregulated on circulating hematopoietic stem cells and leukemia cells to avoid phagocytosis. Cell. 2009;138(2):271-85.

74. Gholamin S, Mitra SS, Feroze AH, Liu J, Kahn SA, Zhang M, et al. Disrupting the CD47-SIRPa anti-phagocytic axis by a humanized anti-CD47 antibody is an efficacious treatment for malignant pediatric brain tumors. Science Translational Medicine. 2017;9(381):eaaf2968.

75. Lin CY, Erkek S, Tong Y, Yin L, Federation AJ, Zapatka M, et al. Active medulloblastoma enhancers reveal subgroup-specific cellular origins. Nature. 2016;530:57.

76. Swartling FJ, Savov V, Persson Al, Chen J, Hackett CS, Northcott PA, et al. Distinct neural stem cell populations give rise to disparate brain tumors in response to N-MYC. Cancer Cell. 2012;21(5):601-13.

77. Zeltzer PM, Boyett JM, Finlay JL, Albright AL, Rorke LB, Milstein JM, et al. Metastasis stage, adjuvant treatment, and residual tumor are prognostic factors for medulloblastoma in children: conclusions from the Children's Cancer Group 921 randomized phase III study. J Clin Oncol. 1999;17(3):832-45.

78. Albright AL, Wisoff JH, Zeltzer PM, Boyett JM, Rorke LB, Stanley P. Effects of medulloblastoma resections on outcome in children: a report from the Children's Cancer Group. Neurosurgery. 1996;38(2):265-71.

79. Clifford SC, Lannering B, Schwalbe EC, Hicks D, O'Toole K, Nicholson SL, et al. Biomarker-driven stratification of disease-risk in non-metastatic medulloblastoma: results from the multi-center HIT-SIOP-PNET4 clinical trial. Oncotarget. 2015;6(36):38827-39.

80. Ramaswamy $\mathrm{V}$, Taylor MD. Medulloblastoma: from myth to molecular. J Clin Oncol. 2017:35(21):2355-63.

81. Lafay-Cousin L, Smith A, Chi SN, Wells E, Madden J, Margol A, et al. Clinical, pathological, and molecular characterization of infant medulloblastomas treated with sequential high-dose chemotherapy. Pediatr Blood Cancer. 2016:63(9):1527-34

82. Holgado BL, Guerreiro Stucklin A, Garzia L, Daniels C, Taylor MD. Tailoring medulloblastoma treatment through genomics: making a change, one subgroup at a time. Annu Rev Genomics Hum Genet. 2017;18:143-66.

83. Cohen BH, Geyer JR, Miller DC, Curran JG, Zhou T, Holmes E, et al. Pilot study of intensive chemotherapy with peripheral hematopoietic cell support for children less than 3 years of age with malignant brain tumors, the CCG-99703 phase I/II study. A report from the Children's Oncology Group. Pediatr Neurol. 2015;53(1):31-46.

84. Rutkowski S, Bode U, Deinlein F, Ottensmeier H, Warmuth-Metz M, Soerensen N, et al. Treatment of early childhood medulloblastoma by postoperative chemotherapy alone. N Engl J Med. 2005;352(10):978-86.

85. Grill J, Sainte-Rose C, Jouvet A, Gentet JC, Lejars O, Frappaz D, et al. Treatment of medulloblastoma with postoperative chemotherapy alone: an SFOP prospective trial in young children. The Lancet Oncology. 2005;6(8):573-80.

86. Geyer JR, Sposto R, Jennings M, Boyett JM, Axtell RA, Breiger D, et al. Multiagent chemotherapy and deferred radiotherapy in infants with malignant brain tumors: a report from the Children's Cancer Group. J Clin Oncol. 2005;23(30):7621-31.

87. Rutkowski S, Gerber NU, von Hoff K, Gnekow A, Bode U, Graf N, et al. Treatment of early childhood medulloblastoma by postoperative chemotherapy and deferred radiotherapy. Neuro-oncology. 2009;1 1(2):201-10.

88. Lafay-Cousin L, Bouffet E, Hawkins C, Amid A, Huang A, Mabbott DJ. Impact of radiation avoidance on survival and neurocognitive outcome in infant medulloblastoma. Current oncology (Toronto, Ont). 2009;16(6):21-8.

89. Cosman R, Brown CS, DeBraganca KC, Khasraw M. Patterns of care in adult medulloblastoma: results of an international online survey. J Neuro-Oncol. 2014;120(1):125-9.

90. Lassaletta A, Ramaswamy V. Medulloblastoma in adults: they're not just big kids. Neuro-oncology. 2016;18(7):895-7.

91. Dufour C, Beaugrand A, Pizer B, Micheli J, Aubelle MS, Fourcade A, et al. Metastatic medulloblastoma in childhood: Chang's classification revisited. Int J Surgical Oncology. 2012;2012:245385.

92. Zapotocky M, Mata-Mbemba D, Sumerauer D, Liby P, Lassaletta A, Zamecnik $J$, et al. Differential patterns of metastatic dissemination across medulloblastoma subgroups. J Neurosurg Pediatr. 2018;21(2):145-52.

93. Mazloom A, Zangeneh AH, Paulino AC. Prognostic factors after extraneural metastasis of medulloblastoma. Int J Radiat Oncol Biol Phys. 2010;78(1):72-8. 
94. von Bueren AO, Kortmann RD, von Hoff K, Friedrich C, Mynarek M, Muller K, et al. Treatment of children and adolescents with metastatic medulloblastoma and prognostic relevance of clinical and biologic parameters. J Clin Oncol. 2016:34(34):4151-60.

95. Gajjar A, Pizer B. Role of high-dose chemotherapy for recurrent medulloblastoma and other CNS primitive neuroectodermal tumors. Pediatr Blood Cancer. 2010;54(4):649-51.

96. Sabel M, Fleischhack G, Tippelt S, Gustafsson G, Doz F, Kortmann R, et al. Relapse patterns and outcome after relapse in standard risk medulloblastoma: a report from the HIT-SIOP-PNET4 study. J Neuro-Oncol. 2016;129(3):515-24

97. Pizer B, Donachie PH, Robinson K, Taylor RE, Michalski A, Punt J, et al. Treatment of recurrent central nervous system primitive neuroectodermal tumours in children and adolescents: results of a Children's Cancer and Leukaemia Group study. European journal of cancer (Oxford, England : 1990). 2011;47(9):1389-97.

98. Morrissy AS, Cavalli FMG, Remke M, Ramaswamy V, Shih DJH, Holgado BL, et al. Spatial heterogeneity in medulloblastoma. Nat Genet. 2017;49(5):780-8.

99. Morrissy AS, Garzia L, Shih DJ, Zuyderduyn S, Huang X, Skowron P, et al. Divergent clonal selection dominates medulloblastoma at recurrence. Nature. 2016;529(7586):351-7.

100. Hill Rebecca M, Kuijper S, Lindsey Janet C, Petrie K, Schwalbe Ed C, Barker K et al. Combined MYC and P53 defects emerge at medulloblastoma relapse and define rapidly progressive. Therapeutically Targetable Disease Cancer cell. 2015;27(1):72-84.

101. Wu X, Northcott PA, Dubuc A, Dupuy AJ, Shih DJ, Witt H, et al. Clonal selection drives genetic divergence of metastatic medulloblastoma. Nature. 2012;482(7386):529-33.

102. Manoranjan B, Wang X, Hallett RM, Venugopal C, Mack SC, McFarlane N, et al. FoxG1 interacts with Bmi1 to regulate self-renewal and tumorigenicity of medulloblastoma stem cells. Stem cells (Dayton, Ohio). 2013;31(7):1266-77.

103. D'Angelo A, Garzia L, Andre A, Carotenuto P, Aglio V, Guardiola O, et al. Prune CAMP phosphodiesterase binds $\mathrm{nm} 23-\mathrm{H} 1$ and promotes cancer metastasis. Cancer Cell. 2004;5(2):137-49.

104. Noguchi T, Oue N, Wada S, Sentani K, Sakamoto N, Kikuchi A, et al. h-Prune is an independent prognostic marker for survival in esophageal squamous cell carcinoma. Ann Surg Oncol. 2009;16(5):1390-6.

105. Galasso A, Zollo M. The Nm23-H1-h-Prune complex in cellular physiology: a 'tip of the iceberg' protein network perspective. Mol Cell Biochem. 2009; 329(1-2):149-59.

106. Diana D, Smaldone G, De Antonellis P, Pirone L, Carotenuto M, Alonzi A, et al. Mapping functional interaction sites of human prune C-terminal domain by NMR spectroscopy in human cell lysates. Chemistry (Weinheim an der Bergstrasse, Germany). 2013;19(37):12217-20.

107. Ferrucci $V$, de Antonellis P, Pennino FP, Asadzadeh F, Virgilio A, Montanaro $D$, et al. Metastatic group 3 medulloblastoma is driven by PRUNE1 targeting NME1-TGF-ß-OTX2-SNAIL via PTEN inhibition. Brain. 2018;141(5):1300-19.

108. Del Valle L, Enam S, Lassak A, Wang JY, Croul S, Khalili K, et al. Insulin-like growth factor I receptor activity in human medulloblastomas. Clinical cancer research : an official journal of the American Association for Cancer Research. 2002;8(6):1822-30.

109. de Pablo F, de la Rosa EJ. The developing CNS: a scenario for the action of proinsulin, insulin and insulin-like growth factors. Trends Neurosci. 1995; 18(3):143-50.

110. Svalina MN, Kikuchi K, Abraham J, Lal S, Davare MA, Settelmeyer TP, et al. IGF1R as a key target in high risk, metastatic medulloblastoma. Scientific Reports. 2016;6:27012.

111. MacDonald TJ, Brown KM, LaFleur B, Peterson K, Lawlor C, Chen Y, et al. Expression profiling of medulloblastoma: PDGFRA and the RAS/MAPK pathway as therapeutic targets for metastatic disease. Nat Genet. 2001;29(2):143-52.

112. Ward SA, Warrington NM, Taylor S, Kfoury N, Luo J, Rubin JB. Reprogramming medulloblastoma-propagating cells by a combined antagonism of sonic hedgehog and CXCR4. Cancer Res. 2017;77(6):1416-26.

113. Thompson MC, Fuller C, Hogg TL, Dalton J, Finkelstein D, Lau CC, et al. Genomics identifies medulloblastoma subgroups that are enriched for specific genetic alterations. J Clin Oncol. 2006;24(12):1924-31.

\section{Ready to submit your research? Choose BMC and benefit from:}

- fast, convenient online submission

- thorough peer review by experienced researchers in your field

- rapid publication on acceptance

- support for research data, including large and complex data types

- gold Open Access which fosters wider collaboration and increased citations

- maximum visibility for your research: over $100 \mathrm{M}$ website views per year

At BMC, research is always in progress.

Learn more biomedcentral.com/submissions 